\title{
Late-Preterm and Full-Term Infant Sleep: Relations with Maternal Cognitions and Nocturnal Behaviors
}

\author{
Marion E. Young \\ West Virginia University
}

Follow this and additional works at: https://researchrepository.wvu.edu/etd

\section{Recommended Citation}

Young, Marion E., "Late-Preterm and Full-Term Infant Sleep: Relations with Maternal Cognitions and Nocturnal Behaviors" (2010). Graduate Theses, Dissertations, and Problem Reports. 4678.

https://researchrepository.wvu.edu/etd/4678

This Dissertation is protected by copyright and/or related rights. It has been brought to you by the The Research Repository @ WVU with permission from the rights-holder(s). You are free to use this Dissertation in any way that is permitted by the copyright and related rights legislation that applies to your use. For other uses you must obtain permission from the rights-holder(s) directly, unless additional rights are indicated by a Creative Commons license in the record and/ or on the work itself. This Dissertation has been accepted for inclusion in WVU Graduate Theses, Dissertations, and Problem Reports collection by an authorized administrator of The Research Repository @ WVU.

For more information, please contact researchrepository@mail.wvu.edu. 
Late-Preterm and Full-Term Infant Sleep: Relations with Maternal Cognitions and Nocturnal

Behaviors

Marion E. Young, M.S.

Dissertation Submitted to the Eberly College of Arts and Sciences

at West Virginia University

in Partial Fulfillment of the Requirements for the Degree of

Doctor of Philosophy
in
Psychology

Katherine Karraker, Ph.D., Chair

Hawley Montgomery-Downs, Ph.D.

Amy Gentzler, Ph.D.

Amy Fiske, Ph.D.

Susan Lynch, M.D.

Department of Psychology

Morgantown, WV

2010

Keywords: Premature Infants; Full-term Infants; Infant Sleep; Maternal Depression 


\section{ABSTRACT \\ Late-Preterm and Full-Term Infant Sleep: \\ Relations with Maternal Cognitions and Nocturnal Behaviors}

Marion E. Young, M.S.

Approximately $13 \%$ of infants born in the United States each year are delivered prematurely, defined as prior to 37 weeks gestation. Among these premature infants, $84 \%$ are born between 32 and 36 weeks gestation (Kelly, 2006). Past research has found that the sleep/wake patterns of late-preterm and full-term infants are different (Gossel-Symank, Grimmer, Korte, \& Siegmund, 2004; Ingersoll \& Thoman, 1999; Ju et al., 1991). However, little is known about psychosocial factors (i.e., maternal sleep-related cognitions and nocturnal behaviors) that may contribute to differences between late-preterm and full-term infant sleep. Few studies have investigated the relations among infant sleep behavior, mothers' cognitions about infant sleep, and mothers' sleep-related behaviors in mothers of full-term and late-preterm infants. Information about these relations might contribute to an understanding of why late-preterm infants might sleep less well than full-term infants.

Results of this study indicated that while not extensive, a few sleep differences do exist between late-preterm and full-term infants at 6 months of age, with late-preterm infants sleeping more during the day than full-term infants. However, relations between infant sleep and maternal cognitions and nocturnal behaviors are less clear. The current sample of late-preterm infant mothers did not endorse cognitions nor participate in nocturnal behaviors that had been previously associated with poorer infant sleep patterns. In some cases, full-term infant mothers were more likely to report certain cognitions (e.g., doubt) than late-preterm infant mothers. This could be related to the psychopathology that was reported in the current sample of full-term infant mothers, including depression. However, late-preterm infant mothers were more vigilant at night than full-term infant mothers, supporting the idea of a slight maternal expectation of infant vulnerability.

Maternal expectations of premature infants in general were also not different between groups with late-preterm infant mothers actually rating unfamiliar full-term infants less favorably than unfamiliar premature labeled infants. While contradictory to what was hypothesized, the findings are in line with research supporting the idea that positive experiences the mothers have had with their own infants would override any negative beliefs held about premature infants. Finally, maternal expectations of infant development also did not differ as was hypothesized. In fact, mothers in the entire sample tended to be accurate reporters of their infant's developmental abilities.

The development of sleep is one of the most important and dramatic processes of infancy and early childhood. The development of sleep/wake patterns in premature infants as an area of research is one that is sparse and the results incongruent. Research investigating sleep in latepremature infants is even less available. Thus, while the current study did not yield a wide range of significant results it is an important first step in continuing to understand the development of sleep patterns in late-premature infants. 


\section{Dedication}

I dedicate this dissertation to my wonderful family and friends. Particularly to my understanding and patient parents, George and Judy, who have put up with these many years of graduate school and research and to a little brother who always had words of encouragement for me no matter the time of day. I also want to say thank you to all of my friends for listening to me and always offering to help me no matter the cost. Finally, I dedicate this work to my late grandparents Carl and Eleanor Young, both of whom believed in diligence, science, and the pursuit of excellence. 


\section{Acknowledgements}

I would like to thank all of those people who helped make this dissertation possible.

First, I wish to thank my advisor, Dr. Katherine Karraker for all her encouragement, guidance, patience, and support. Her sincere dedication and interests in behavioral science, psychology, and the parent-infant relationship have been a great inspiration to me. Also I would like to thank my committee members, Dr. Hawley Montgomery-Downs, Dr. Susan Lynch, Dr. Amy Gentzler, and Dr. Amy Fiske for their very helpful comments, suggestions, and insights. I would also like to thank the medical staff at the Neonatal Follow-Up Clinic, who provided invaluable support and suggestions throughout this process. This research would also not have been possible without funding from the West Virginia University Department of Psychology and the Behavioral and Biomedical Training Scholarship. Finally, sincerest thanks to all of the families who graciously welcomed me into their homes and made this research possible. 
Table of Contents

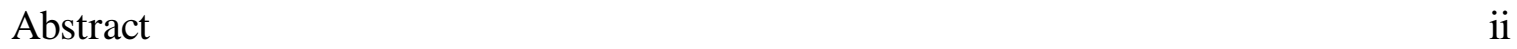

Dedication $\quad$ iii

Acknowledgments $\quad$ iv

Table of Contents $\quad$ V

List of Tables

Introduction $\quad 1$

$\begin{array}{ll}\text { Methods } & 22\end{array}$

$\begin{array}{ll}\text { Results } & 31\end{array}$

$\begin{array}{ll}\text { Discussion } & 40\end{array}$

$\begin{array}{ll}\text { References } & 54\end{array}$

$\begin{array}{ll}\text { Appendix A: Brief Symptom Inventory } & 78\end{array}$

Appendix B: Infant and Mother Activity Charts 82

Appendix C: Maternal Cognitions about Infant Sleep Questionnaire 87

Appendix D: Infant Sleep Vignettes Interpretation Scale $\quad 90$

Appendix E: Vulnerable Child Scale 96

Appendix F: Bayley Expectations Questionnaire $\quad 98$

Appendix G: Background Information Form 102 


\section{List of Tables}

Table 1: Premature Birth Statistics

Table 2: Demographic characteristics of late-preterm and full-term infant mothers

Table 3: Medical and anthropomorphic measures for late-preterm and full-term infants and mothers

Table 4: Demographic information for late-preterm and full-term infants

Table 5: Maternal depression history

Table 6: Global maternal scores (average item ratings) for the Brief Symptom Inventory

subscales

Table 7: Late-preterm and full-term infant sleep indices summary scores (average per 24-hour period)

Table 8: Descriptive information on Bayley expectations

Table 9: Total Scores for the Maternal Cognitions about Infant Sleep Questionnaire, the Vulnerable Child Scale, and the Stern-Karraker Infant Rating Scale 
Late-Preterm and Full-term Infant Sleep: Relations with Maternal Cognitions and Nocturnal Behaviors

Approximately $13 \%$ of infants born in the United States each year are delivered prematurely, defined as prior to 37 weeks gestation. Among these premature infants, $84 \%$ are born between 32 and 36 weeks gestation (Kelly, 2006; see Table 1). This subgroup of premature infants has a high survival rate $(98 \%)$ and typically only spends a few days or weeks in the Neonatal Intensive Care Unit (Kelly, 2006). Most of these infants are considered "healthy" as they quickly meet the requirements for discharge (i.e., nipple feeding, consistent weight gain, complete reduction in apneic spells, and temperature stability) and usually require no more than a few days of respiratory support and antibiotic treatment for sepsis associated with prematurity (Verma, Sridhar, \& Spitzer, 2003). However, these late-term premature infants (hereafter referred to as "late-preterm" infants) are not as biologically mature as full-term infants, and therefore are re-admitted to the hospital more frequently than full-term infants (Engle, Tomashek, Wallman, \& the Committee on the Fetus and Newborn, 2007).

Recently, the medical literature has begun to focus on this subgroup of premature infants, emphasizing that even though these infants are healthy, they may experience developmental disadvantages because of their lack of developmental maturity at birth (Kelly, 2006). In contrast, relatively little psychological research has focused on this unique subgroup of premature infants. Much of the existing psychological literature has focused on the differences between premature and full-term infants in general; when subgroups are examined, the majority of studies have focused on premature infants born at less than 32 weeks gestation or those infants born at less than 1500 grams. Thus, one focus of the present study was on differences between late-preterm and full-term infant sleep. 
Much of the extant literature on premature infants has shown that these infants demonstrate less consistent behavioral patterns than their full-term counterparts, and thus are reported as challenging for parents (Eckerman, Hsu, Molitor, Leung, \& Goldstein, 1999; Olafsen, Kaaresen, Handegard, Ulvund, Dahl, \& Ronning, 2008). These challenges may be particularly relevant for the mothers of late-preterm infants when considering the consolidation of the sleep/wake cycle in the early months of life. Late-preterm infants are born before their nervous systems are fully developed, placing the infant at risk for long-term health consequences (Engle et al., 2007). Clinical reports in the medical literature comparing later preterm and fullterm infants have found a higher risk for disorders (e.g., cerebral palsy, speech disorders) behavioral abnormalities, and reduced social competence (as cited in Engle et al., 2007). However, the consolidation of sleep/wake cycles and the impact it may have on mothers of latepreterm infants has not been fully investigated.

Indeed, some of the most common behavioral adjustments for mothers of full-term infants and young children concern sleep issues, such as night waking in infancy and routine bedtime struggles in young children (Morrell, 1999). Night waking is a normative behavior that occurs in early infancy in order to meet the nutritional needs of the infant (DeLeon \& Karraker, 2007). By 3-4 months of age most full-term and some premature infants no longer require nighttime feedings and while all infants continue to awaken at night they do not typically require parental assistance to return to sleep (Anders \& Taylor, 1994; DeLeon \& Karraker, 2007). However, premature infants may need to continue night time feedings due to nutritional needs. Night waking in infancy becomes a problem when the infant, who no longer requires feedings, signals to the parent to obtain assistance in returning to sleep. Although this behavior tends to decrease with age, a significant minority of infants continue to awaken their parents at night 
beyond early infancy (Richman, 1981). These infants who continue to awaken at night (more than 3 times per night) are referred to in the literature as chronic night wakers and their nighttime behaviors are often a challenge for their parents. Their parents can experience sleep fragmentation and sleep deprivation, which can result in parental daytime fatigue and negative mood (Pilcher \& Huffcutt, 1996). Thus, if late-preterm infants are disorganized or delayed in developing organization of their sleep/wake patterns this could present a challenge for their mothers.

With the potential deleterious effects of infant night waking on parents and the disorganization of sleep in late-preterm infants it is important to investigate differences in the sleep patterns of late-preterm infants and full-term infants. Parenting can be a difficult task and one that can be further exacerbated by premature birth. Research has found that mothers of premature infants (who are also low birth weight) tend to report higher levels of stress and anxiety about parenting than mothers of full-term infants (Gennaro, 1988; Meyer, Garcia, \& Seifer, 1995). As parenting is already a challenge for these mothers, parenting abilities could be further compromised when coupled with the stress and anxiety associated with potential premature infant sleep difficulties.

Premature infants' irregularities in maintaining homeostasis are often reflected in their irregular sleep patterns in early infancy (Davis \& Burns, 2001; Minde, 2000). Specifically, the premature infant tends to signal more to the parent at night than do their full-term counterparts, resulting in sleep fragmentation and deprivation for the parent. The present study investigated sleep differences between late-preterm and full-term infants at 6 months corrected age. Corrected age is calculated by subtracting the number of weeks the infant was born before 40 weeks of gestation from the infant's age since birth (Bayley, 2006). For example, a 14-month-old infant, 
born at 28 weeks gestation has a corrected age of 11 months. Six months of age was chosen as research has found that approximately half (or more) of full-term infants sleep through the night at this age. Night waking is expected by many parents during early infancy, but when the night waking persists the behavior becomes a challenge for many parents (Karraker \& Young, 2007). From 0 to 3 months of age, it is difficult to disentangle sleep and excessive crying/fussiness problems because sleep architecture is less consolidated at this time and the two behaviors are interrelated (Bayer, Hiscock, Hampton, \& Wake, 2007). However, by 3-6 months of age, most infants have established a sleep/wake cycle and the cry/fuss behavior has decreased; thus sleep problems can be more easily detected (Bayer et al., 2007).

Research by Chyi and colleagues (Chyi, Lee, Hintz, Gould, \& Sutcliffe, 2008) provided an argument for the importance of investigating differences between late-preterm (born between 32 and 36 weeks) and full-term infants. The authors argue that researchers have often disregarded these group differences because it is believed that the development of late-preterm infants is similar to that of full-term infants. However, it is important to note that even though some of the organ systems of some late-preterm infant are mature, their brains and central nervous systems are more immature than those of the full-term infant (Chyi, et al., 2008). As the central nervous system and brain continue to mature after birth, the initial developmental lag of the late-preterm infant may persist and lead to differences from full-term infants in sleep patterns at 6 months.

Additionally, differences in sleep-related parenting of late-preterm versus full-term infants have not been investigated. This type of research is needed as late-preterm infants comprise a large proportion of premature infant births; in addition, these infants may be at risk for sleep disturbances as compared to full-terms, thus potentially increasing parents' (especially 
mothers') feelings of stress and anxiety about parenting. Mothers' sleep-related cognitions may be particularly relevant as they may be associated with mothers' choices of nocturnal behaviors and with their premature infant's sleep. For example, research has found that parental cognitions, in the form of developmental expectations, play a major role in guiding parent-child relationships and child development (Gottoman, Katz, \& Hooven, 1996; Miller, 1995). Studies have shown that these parental expectations or cognitions impact the manner in which parents interpret and respond to child behaviors. Research has also shown that mothers of premature infants (born at less than 1500 grams) view their child as more vulnerable (i.e., more susceptible to health problems) than do mothers of full-term infants (Perrin, West, \& Culley 1988). This perceived premature infant vulnerability could potentially lead to differences in how mothers interpret and respond to late-preterm and full-term infant sleep.

The general goal of the current study was to investigate not only similarities and differences in late-preterm and full-term infant sleep, but also specific differences between mothers of late-preterm and full-term infants that may influence infant sleep/wake patterns. The following sections discuss sleep patterns and night waking in late-preterm and full-term infants, the impact of night waking on mothers, and how sleep-related cognitions may impact latepreterm and full-term infant sleep.

\section{Sleep and night waking in infancy}

The full-term newborn infant spends approximately 12-16 hours per day sleeping, which is distributed across several brief cycles of sleeping (Kahn, Dan, Groswasser, Franco, \& Sottiaux, 1996). Infant sleep has been described as “polyphasic.” Specifically, newborn infant sleep is divided into 3- to 4-hour sleep cycles throughout a 24-hour period (Anders \& Taylor, 
1994). Full-term infants, by approximately 6 to 9 months of age, are typically awake for the majority of the day (with 1-2 brief naps) and sleep continuously through the night, with no more than one awakening per night for feeding purposes (Ingersoll \& Thoman, 1999). Weissbluth (1995) found that full-term infants took three or four naps at 6 months and as few as two naps by 9 to 12 months.

Infant sleep is also divided into two distinct sleep states. These sleep states are referred to as Active Sleep (AS) and Quiet Sleep (QS) (Anders \& Taylor, 1994; Middlemiss, 2004). Active sleep is characterized by the display of rapid eye movements, and is similar to adult REM sleep (Anders \& Taylor). In contrast, quiet sleep is characterized by a lack of rapid eye movements and a decrease in respiratory rate, similar to adult non-REM sleep (Anders \& Taylor, 1994; Middlemiss, 2004). Quiet sleep and active sleep states also differ in the level of arousal exhibited by the infant (Middlemiss, 2004). Explicitly, Mosko et al. (1996) reported that during quiet sleep infants are more difficult to arouse than during active sleep (as cited in Middlemiss, 2004). Researchers have postulated that the greater amount of active sleep as compared to quiet sleep in early infancy results in infant night wakings (as cited in Middlemiss, 2004). Signaled night wakings may also occur because of the infant's nutritional needs in early infancy (DeLeon \& Karraker, 2007). As infants mature they no longer physiologically require night feedings and infants begin acquiring the ability to self-soothe at night, thus not requiring parental assistance to return to sleep. However, those infants who have difficulty learning to self-soothe will continue to signal to parents at night (Anders \& Taylor, 1994; Middlemiss, 2004).

Parental assistance offered to these infants may be breast feeding, putting the infant to bed asleep, and co-sleeping, behaviors that have all been proposed as causes of continued or increased infant night waking (Anders \& Taylor, 1994; Hayes, Roberts, \& Stowe, 1996). Infants 
who are breast fed also tend to exhibit more night wakings as the infant develops associations between being fed and going to sleep. This association is stronger for breast-fed infants as breastfed infants are fed more frequently during early infancy because breast milk provides less concentrated nutrition than formula, and thus the infant wakes up hungry more often (DeLeon \& Karraker, 2007; Mindell, 1997). As a result, these infants require a feed before they can return to sleep at night (Burnham, Goodlin-Jones, Gaylor, \& Anders, 2002; DeLeon \& Karraker, 2007). Research has also found that those infants who are put to bed asleep spend more time awake at night and are less able to effectively soothe themselves when awakened than infants who are put to bed while still awake (Burnham, Goodlin-Jones, Gaylor, \& Anders, 2002; DeLeon \& Karraker, 2007). Adams, Jones, Esmail, and Mitchell (2004) investigated 61 potential factors that were associated with the age of first sleeping through the night. Those infants who did not co-sleep slept through the night sooner than those infants who did co-sleep more than 2 hours per night (Adams et al., 2004).

As was mentioned previously, signaled night wakings in early infancy, while normative, typically require parental response in order to aid the infant's return to sleep (Anders \& Taylor, 1994). Thus, the sleep of the infant and the parent are intertwined. Chronic night waking becomes a problem for the parent as it infringes on the amount of undisturbed sleep parents get at night, resulting in sleep fragmentation and potential sleep deprivation. This lack of sleep can cause daytime fatigue, mood disturbances, and other forms of impairment. For example, research has found that mothers of infants who awoke more than three times per night reported greater levels of daytime fatigue (Dennis \& Ross, 2003) and more depressive symptoms than those mothers whose infants did not wake up as often (Dennis \& Ross, 2003; Karraker \& Young, 
2007). Research has also found that mothers of infants who frequently awaken their parents at night tend to doubt their parental competence more than do other mothers (Morrell, 1999).

For women the postpartum period can be characterized as a time of high vulnerability to emotional stress (Lau \& Morris, 2003). Concurrently, mothers of young infants often experience sleep loss and fragmentation because of the need to feed and care for their infants during the night. Mothers' vulnerability to stress can be exacerbated by the change in both the quality and quantity of sleep that they experience (Dennis \& Ross, 2005). Indeed, research has found that infant night waking and the resulting maternal fatigue is associated with increased depression (Dennis \& Ross, 2005). However, the authors point out that the causal pathway is unclear. It could be that the high frequency of night waking increases maternal sleep fragmentation, which in turn increases the reporting of maternal depression. Conversely, it has been postulated that the presence of prior depressive symptomatology influences maternal perceptions (Warren, Howe, Simmons, \& Dahl, 2006) and parenting behaviors (National Institute of Child Health and Human Development Early Child Care Research Network [NICHD ECCRN], 1999), which in turn perpetuate infant night waking.

\section{General Impact of Sleep Deprivation on Non-Postpartum Adults}

Sleep deprivation not only can impact mothers' depression, but can also have an effect on their cognitive performance. Results of one study found that one night of sleep deprivation (25.7 hours of wakefulness) negatively impacted alertness, vigilance, reaction time, and error correction (Horn et al., 1983; Hsieh, Cheng, \& Tsai, 2007). A meta-analysis of 19 studies investigated the effects of sleep deprivation on daytime functioning (Pilcher \& Huffcutt, 1996). Interestingly, the authors noted that as compared to long-term ( $>45$ hours of wakefulness) or 
short-term ( $\leq 45$ hours of wakefulness) total sleep deprivation, cumulative partial sleep deprivation (< five hours of sleep in a 24-hour period) resulted in worse overall functioning (Pilcher \& Huffcutt, 1996). For parents of frequent night waking infants these results are of great importance. Specifically, parents of chronically waking infants, while not awake all night, still experience chronic sleep fragmentation and partial sleep deprivation, resulting in potential deleterious effects on parental daytime functioning. For mothers of late-preterm infants, whose infants are at a potential greater risk for sleep disturbances than full-term infants, sleep fragmentation and partial sleep deprivation may add more stress and anxiety to the mothers' lives and may negatively impact parenting abilities and the mother-infant relationship.

Infant night waking and maternal depression can also be exacerbated by premature birth. Premature infants may lag behind full-term infants in developing the ability to self-soothe. This developmental lag suggests that infants born prematurely may be at an increased risk for needing parental assistance to return to sleep when awakened at night. The resulting maternal fatigue associated with infant night waking could then place the premature infants' mothers at a greater risk for depression than full-term infants' mothers. This increased risk for depression as a result of interrupted nighttime sleep is further compounded by the already elevated levels of depression and anxiety in this population of mothers. Research has found that mothers of premature infants continue to exhibit high levels of anxiety and depression even 6 months after infant discharge from the neonatal intensive care unit. Indeed, Meyer and colleagues found that $28 \%$ of mothers of premature infants who were hospitalized for several weeks displayed clinically significant levels of depression and anxiety as compared to $10 \%$ in the full-term infant control sample (Meyer, Garcia, \& Seifer, 1995). 


\section{Premature Infant Sleep}

Ingersoll and Thoman (1999) reported that premature infants born at 33 and 35 weeks gestational age and at less than 1500 grams demonstrated more irregular sleep/wake patterns than did full-term newborns. Researchers recorded the sleep/wake states of 95 premature infants for a period of 72 hours. Even at term age premature infants showed more transitions between sleep and wake states than did full-term neonates, resulting in high sleep fragmentation (Ingersoll \& Thoman, 1999).

As was mentioned previously, studies of premature infants and late-preterm infants in particular, are limited. Those studies investigating late-preterm infant sleep and full-term infant sleep did find some differences. For example, Gossel-Symank, Grimmer, Korte, \& Siegmund (2004) used actigraphy to monitor the sleep/wake patterns and quality of sleep of 17 premature (24-34 weeks gestation) and 8 full-term 20-month-old infants over a 10-day period. It is important to note that while actigraphy is a useful means of monitoring sleep in older children and adults, this method has not been validated for infants (Acebo, Sadeh, Seifer, Tzischinsky, Wolfson, Hafer, \& Carskadon, 1999). The premature infants slept less at night and had lower quality sleep (i.e., less restful nighttime sleep - assessed as high amounts of large movements during sleep) than their full-term counterparts (Gossel-Symank et al., 2004).

Ju et al. (1991) investigated maternal reports at 7 months corrected age of premature (born between 32 and 35 weeks gestation) and full-term infant sleep utilizing a 1-week sleep diary. Results indicated significant differences in longest segment of sleep (8.2 hours for premature versus 9.6 hours for full-term) and the average number of night wakings ( 3 per night for premature infants versus 1 for full-term infants); however, no group differences were found 
in the total amount of sleep (Ju et al., 1991). Indeed, $41 \%$ of premature infants awakened three or more times per week as compared to the full-term infants who awakened fewer than three times per week (Ju et al., 1991). It is important to note that although the premature and full-term infants in this study did not differ in the number of feedings per day, premature infants did receive more feedings between midnight and 5 a.m. than full-term infants $(0.31$ for premature infants versus 0.10 for full-term infants). This difference in night feedings (premature infants awakening at night and their mothers feeding them in order to return the infant to sleep) may have contributed to the significant difference in the number of infant night wakings.

In sum, research on late-preterm infant sleep indicates that there are numerous physiological explanations (e.g., breast-feeding, arousability) for differences between latepreterm and full-term infant sleep. However, these studies failed to consider potential psychosocial influences (e.g., maternal sleep-related cognitions or nocturnal behaviors) that may help explain potential differences between late-preterm and full-term infant sleep.

\section{Parental cognitions and infant sleep}

Infant night wakings have been found to be associated with parental attitudes and behaviors. For example, Goldberg and Marcovitch (1986) found that premature infants emit less distinct crying signals than do full-term infants. As a result, mothers of premature infants reported more difficulties than mothers of full-term infants in anticipating their infants' needs (Goldberg \& Marcovitch, 1986). Thus, mothers' difficulty in anticipating their premature infant's needs could potentially heighten their sensitivity and vigilance, especially during the night. As a result, these mothers may become overly attuned to infant restlessness and intervene by waking the infant (Ju et al., 1991). 
Conversely, mothers of premature infants may become less sensitive than mothers of fullterm infants to infant restlessness. Because mothers of premature infants cannot tell why their infant is signaling, they may come to ignore the signal entirely. The current study examined the question of whether mothers of premature infants are more or less responsive to their infants' night-time signals than are mothers of full-term infants. Another potential explanation for the differences between late-preterm and full-term infant sleep relates to negative maternal perceptions and expectations regarding their prematurely born infant. Maternal perceptions and expectations for their infants can have a major impact on parenting (Stern, Karraker, McIntosh, Moritzen, \& Olexa, 2006). Previous research has found that individuals hold a negative set of beliefs or perceptions about premature infants, which in turn can produce negative adult behavior toward the infant (Stern et al., 2006). This tendency has been labeled prematurity stereotyping by Stern and colleagues. Research has confirmed that individuals (both parents and non-parents) rate infants labeled premature as less physically attractive, less sociable, less cognitively competent, less behaviorally appealing, and littler than infants' labeled full-term (Stern \& Karraker, 1990). Although the cognitive and behavioral effects of prematurity stereotyping on adult behaviors toward premature infants have been demonstrated in past research (Stern \& Karraker, 1990; Stern et al., 2006), less is known about the effect that prematurity stereotyping may have on maternal behaviors that may be associated with late-preterm infant sleep. Thus, the present study investigated the associations between maternal behaviors, late-preterm infant sleep, and prematurity stereotyping.

Previous research has also demonstrated that full-term infant sleep behaviors are correlated with specific maternal cognitions. For example, Morrell (1999) found that dysregulated full-term infant sleep is correlated with particular maternal cognitions. Specifically, 
mothers of infants who chronically woke at night reported cognitions related to difficulties with setting limits, anger, and doubt (Morrell, 1999). Specifically, parents who had difficulty establishing a routine at night (i.e., setting limits cognitions) or became angry when their infant awoke (i.e., anger cognitions) had infants who awoke multiple times throughout the night. It could be argued that parents of chronically waking infants endorse specific sleep-related cognitions with regard to their infant, which then may lead to parenting behaviors that encourage night waking (e.g., co-sleeping, putting the infant to bed asleep, reactivity to infant signals). Conversely, it may be that the sleep problems of the infant induce the endorsement of specific sleep-related cognitions.

Recent research by Sadeh, Flint-Ofir, Tirosh, and Tikotzky (2007) found that parents of full-term infants from a clinical sample (i.e., infants whose parents sought help at a local sleep lab) were more likely than parents of infants in a control sample to endorse cognitions related to not being able to set limits at night (e.g., it is alright to allow my child to cry at night) and distress orientations (e.g., my child might die while sleeping) with regard to infant night-time behavior. However, even though these parents indicated that limit setting was an appropriate strategy to utilize in a hypothetical situation, difficulties with setting limits on their own infant's nighttime behavior was indicated as a parental problem by the participants (Sadeh et al., 2007). The authors suggest that the disconnect between what parents know to be the "right" response and the parents' inability to implement an effective behavioral response with their own infant results in an inconsistent behavior pattern that does not help the infant calm at night or develop effective self-soothing capabilities (Sadeh et al., 2007).

In sum, this research extends previous research by investigating the potential differences in late-preterm and full-term infant sleep at 6 months, an age not previously investigated. 
Specifically, if late-preterm infants are having poorer sleep than their full-term counterparts it could be that the cognitive sets (i.e., expectations, perceptions, cognitions) of their parents differ. In other words, how mothers perceive their infants and their sleep can affect mothers' responses to their infants and selection of specific bedtime behaviors, which in turn may influence infant night waking.

\section{Statement of the Problem}

Past research has found that the sleep/wake patterns of late-preterm and full-term infants are different (Gossel-Symank, Grimmer, Korte, \& Siegmund, 2004; Ingersoll \& Thoman, 1999; Ju et al., 1991). However, little is known about psychosocial factors (i.e., maternal sleep-related cognitions and nocturnal behaviors) that may contribute to differences between late-preterm and full-term infant sleep. Few studies have investigated the relations among infant sleep behavior, mothers' cognitions about infant sleep, and mothers' sleep-related behaviors in mothers of fullterm and late-preterm infants. Information about these relations might contribute to an understanding of why late-preterm infants might sleep less well than full-term infants.

The current study also has important implications for potential interventions. Specifically, most clinical interventions for chronic night waking infants are based on training parents to extinguish their involvement during the night (Mindell, 1999; Sadeh, 2005). However, most of these approaches tend to ignore the underlying cognitive components that may be driving the selection of specific nighttime behaviors (Sadeh, 2005). Mothers of late-preterm infants may think differently about infant sleep or engage in different sleep-related behaviors (e.g., cosleeping, putting the infant to bed asleep, breast feeding, and vigilance) than mothers of full-term infants. Therefore, the current study began by investigating differences in sleep patterns of late- 
preterm and full-term infants, and differences in sleep-related cognitions and behaviors of the mothers of these two groups of infants. The following research questions and related hypotheses were addressed.

\section{Research Question 1}

Do the sleep behaviors of 6-month-old late-preterm and full-term infants differ?

Hypothesis 1a: Late-preterm infants will awaken and signal more frequently at night than full-term infants.

Hypothesis $1 b$ : Late-preterm infants will spend less time asleep at night than full-term infants.

Rationale for Hypotheses $1 a-1 b$. Previous research has found that premature infants sleep less well as newborns (Ingersoll \& Thoman, 1999) and at 20 months (Gossel-Symank, Grimmer, Korte, \& Siegmund, 2004) than full-term infants. Research has found that approximately half (or more) of full-term infants sleep through the night at 6-months. Although night waking is expected by many parents during early infancy, when the night waking persists, the behavior becomes a challenge for many parents (Karraker \& Young, 2007). Given that infant sleep patterns tend to be fairly stable (Kahn, Dan, Groswasser, Franco, \& Sottiaux, 1996), it was expected that premature infants would awaken more frequently and sleep less in total than fullterm infants at 6 months corrected age.

Hypothesislc: Late-preterm infants will take more frequent naps during the day than fullterm infants. 
Rationale. To date there is little research about the nap taking behaviors of infants. Research has found that premature infants tend to exhibit less effective self-regulation abilities than full-term infants (Davis \& Burns, 2001). Specifically, premature infants have been observed to sleep less well at night and display more sleep/wake transitions than full-term infants (Ju et al., 1991; Keener, Zeanah, \& Anders, 1988). It could be postulated that premature infants will take more naps during the day to compensate for their interrupted nighttime sleep.

Hypothesis $1 d$ : Late-preterm infants will be more likely to signal to mothers by crying when they awaken at night than full-term infants.

Rationale. Previous research has found that many of the deficits seen in premature infants are related to their inability to maintain homeostasis and their lack of effective self-regulation capabilities (Davis \& Burns, 2001; Minde, 2000). As infants mature they increasingly acquire the ability to self-soothe (self-regulate) at night, thus not requiring parental assistance to return to sleep. Premature infants may lag behind full-term infants in developing this self-regulatory ability (i.e., self-soothing). As a result, premature infants may more frequently signal to their parents via crying as they are unable to return to sleep on their own.

\section{Research Question 2}

In what ways do the sleep-related cognitions and behaviors of mothers of 6-month-old late-preterm and full-term infants differ?

Hypothesis 2a: Mothers of late-preterm infants will view their infants as more vulnerable than mothers of full-term infants. 
Rationale. Research has shown that mothers of premature infants view their child as more vulnerable (i.e., more susceptible to health problems) than do mothers of full-term infants (Perrin, West, \& Culley, 1988). In this early study, the sample consisted of infants born prematurely and at less than 1500 grams. For the present study, it was believed that because the infant is thought of as premature the mother will view the infant as more vulnerable than will full-term infant mothers. This maternal perception of premature infants as vulnerable may influence how the mothers of premature infants think about their infant's sleep (e.g., doubt and safety cognitions) that may in turn translate into specific maternal sleep behaviors (e.g., cosleeping, putting the infant to bed asleep).

Hypothesis $2 b$ : Mothers of late-preterm infants will report more doubt, safety, and anger cognitions than mothers of full-term infants.

Rationale for hypotheses $2 b$. Based on previous research premature infants in the proposed study were expected to sleep less well than full-term infants. The expected sleep differences may drive the proposed maternal cognition differences or the proposed maternal cognition differences may influence the potential infant sleep differences. Specifically, mothers of premature infants may frame their cognitions about their baby's sleep in terms of safety. In other words, their potential hypervigilence and engagement in specific nocturnal behaviors may be associated with specific concerns the mother has for the infant's safety at night. Mothers of premature infants may also frame their cognitions about their infant's sleep in terms of doubt. Thus, their potential hypervigilence and engagement in specific nocturnal behavior may be associated with concerns the mother has regarding her competency as a parent of a premature infant. Conversely, a lack of hypervigilence or disengagement in certain nocturnal behaviors may be associated with anger the mother feels at the night waking behavior of her premature infant. 
Hypothesis 2c: Mothers of late-preterm infants will be more vigilant at night than mothers of full-term infants.

Hypothesis 2d: Mothers of late-preterm infants will more frequently engage in sleeping practices that have been previously shown to promote signaled night waking (e.g., co-sleeping, vigilance, putting infant in bed asleep) than will mothers of full-term infants.

Rationale. Because mothers of premature infants know that their infants may be at a higher risk for SIDS they may become hypersensitive to their infant's state changes (Horne et al., 2001). Thus, mothers may become highly attuned to any infant restlessness and intervene by waking the infant. Unfortunately, any intervention, such as feeding, may potentially perpetuate the infant night awakening behavior (Ju et al., 1991). Research by Morrell and Steele (2003) found an indirect link between maternal cognitions and signaled infant night waking. Specifically, mothers who endorsed cognitions associated with limit setting and anger at their infants at night were more likely to use physical comforting strategies at night. Consequently, the use of physical comforting predicted continual infant night waking (Morrell \& Steele, 2003). Therefore, mothers' perceptions of infant vulnerability may lead mothers of premature infants to engage in behaviors (e.g., co-sleeping, putting the infant to bed asleep) that may contribute to perpetuating infant night waking. In other words, it could be that the nocturnal behaviors are mediating the relation between maternal sleep-related cognitions and infant night waking. 


\section{Research Question 3}

Do maternal expectations of 6-month-old late-preterm and full-term infants differ?

Hypothesis 3a: Mothers of late-preterm infants will underestimate (i.e., expect the infant to fail more items than they pass) their infant's performance on the Bayley Scales of Infant and Toddler Development than mothers of full-term infants.

Rationale for hypothesis $3 a$. Parents hold expectations or goals about what their infant or child should be able to do developmentally (van Beek, Genta, Costabile, \& Sansavini, 2006). If these expectations are unrealistic it may lead to disappointment and negative perceptions of the infant (van Beek, Genta, Costabie, \& Sansavini, 2006). Research postulates that parental expectations may be altered when an infant is born prematurely. For example, research has shown that mothers of premature infants (born at less than 1500 grams) view their child as more vulnerable (i.e., more susceptible to health problems) than do mothers of full-term infants (Perrin, West, \& Culley, 1988). As a result of this possible view of the late-preterm infant as vulnerable less favorable developmental outcomes may be anticipated by the mother. It is also believed that the maternal underestimation scores will be associated with more fragmented latepreterm infant sleep. It could be that the mother expects the infant to not do as well because of a lack of restorative sleep the previous weekend.

\section{Research Question 4}

Does prematurity stereotyping moderate the relation between late-preterm and full-term infant sleep? 
Hypothesis 4a: Mothers of late-preterm and full-term infants will view unfamiliar infants labeled as premature more negatively than unfamiliar infants labeled as full-term.

Rationale. Research has shown that mothers of full-term infants and mothers of premature infants rate infants labeled premature as less physically attractive, less sociable, less cognitively competent, less behaviorally appealing, and littler than infants' labeled full-term (Stern \& Karraker, 1990; 2006).

Hypothesis $4 b$ : Late-preterm infant mothers who engage in prematurity stereotyping will have infants who demonstrate poorer sleep patterns than late-preterm infant mothers who do not engage in prematurity stereotyping.

Rationale. Maternal perceptions and expectations can affect both parenting practices and infant behavior via a self-fulfilling prophecy process (Stern, Karraker, McIntosh, Moritzen, \& Olexa, 2006). In this process a mother treats her infant according to her perceptions and expectations for that infant, eventually producing the infant behaviors that she expects (Stern et al., 2006). Research has found that those mothers of premature infants who engaged in prematurity stereotyping had more negative interactions with their own infant than mothers who did not (Stern et al., 2006). These findings regarding prematurity stereotyping could be extended to the area of late-preterm infant sleep. Specifically, if a mother perceives an unfamiliar prematurely labeled infant more negatively than an unfamiliar full-term labeled infant it could be assumed that she holds negative beliefs about premature infants in general, including her own. Therefore, how the mother perceives her infant and her tendency to engage in prematurity stereotyping could affect her responses to and selection of specific bedtime behaviors (e.g., co- 
sleeping, putting the infant to bed asleep) that in past research have been associated with greater infant night waking. 
Method

\section{Participants and Procedure}

The sample consisted of 27 mothers of late-preterm infants who were delivered between 32 and 37 weeks gestation (M=34.41 weeks, range 32-36 weeks) and 27 mothers of healthy, fullterm infants, who were delivered between 38 and 42 weeks gestation ( $M=39.33$ weeks, range 3840 weeks). The infants did not have any current major medical problems (e.g., acute respiratory disease) and were not on medications at the time of the study, as verified by their mother. Data were collected when the infants were 6 to 7 months corrected age. Only mothers who spoke English and were at least 18 years of age with no severe current medical or psychological conditions (e.g., bipolar disorder, schizophrenia) as determined by the Brief Symptom Inventory (Derogatis, 2004) were included in the study.

Mothers of premature infants were recruited from the Ruby Memorial Hospital Neonatal Follow-up Clinic by the primary investigator when the infant was approximately 4 months corrected age. At this time the mother provided consent to participate in the current study. Contact information was also obtained so the primary investigator could contact the mother to schedule the home visit. Mothers were then sent a reminder letter when the infant was 5 months corrected age and were contacted by phone two weeks later to schedule the home visit. Mothers who agreed to continue participation were sent a packet containing a letter describing the study in more detail, the study questionnaires, including the Brief Symptom Inventory (Derogatis, 2004), the Vulnerable Child Scale (Perrin, West, \& Culley, 1989), Maternal Cognitions about Infant Sleep Questionnaire (Morrell, 1999), the Infant Sleep Vignettes Interpretation Scale (Sadeh et al., 2007), and the Infant Care Diary (Karraker \& Cottrell, 2002). The mother was 
instructed to complete the questionnaires and sleep diary the weekend prior to the home visit (from Friday at 4:00 p.m. to Monday at 8:00 a.m.). Upon arrival at the home, mothers completed the Bayley Expectations Questionnaire (Karraker, 2002) and then the infant's current developmental status was assessed and videotaped (for potential later use) by the primary investigator using the Bayley Scales of Infant and Toddler Development (BSID-III; Bayley, 2006).

Finally, mothers watched four prerecorded DVDs of 4-month-old full-term infants who were shown playing with an assortment of non-sex-typed toys for approximately 5 minutes. Two of the infants were described as having been born prematurely and the other two infants were described as having been born at full term. After viewing each video, mothers completed the Stern-Karraker Infant Stereotyping Scale (Stern \& Karraker, 1990). Mothers were then debriefed about the deception involved in this assessment. Specifically, mothers were informed that all infants viewed were in fact full-term infants and that infant gender had also been varied. Mothers were then thanked for their participation, provided with a mental health referral list, and given a $\$ 30.00$ gift card and a WVU t-shirt or hat for their infant.

Full-term infants and their mothers were recruited from the Ruby Memorial Hospital Department of Obstetrics and Gynecology, county birth records, and fliers placed in local pediatric offices. Mothers were sent an introductory letter when the infant was 5 months old and then were contacted by phone two weeks later to schedule the home visit. The protocol for the full-term mothers was the same as that used for the late-preterm infants. 


\section{Measures}

Maternal well-being. (Appendix A). The Brief Symptom Inventory (BSI; Derogatis, 2004) was used to determine if the mother had any current psychological symptoms. The BSI is a 53-item measure that asks the participant to respond to how distressed she was by certain problems (e.g., nervousness or shakiness inside) over the last week (Derogatis, 2004). The items were rated on a 4-point Likert scale from 0 (not at all) to 4 (extremely) with the majority of reliabilities for this sample being acceptable. The BSI was divided into nine symptom subscales: somatization consisted of six items $(\alpha=.66)$, obsession-compulsion consisted of six items ( $\alpha=.87$ ), interpersonal sensitivity consisted of four items $(\alpha=.79)$, depression consisted of six items $(\alpha=.84)$, anxiety consisted of six items $(\alpha=.63)$, hostility consisted of five items $(\alpha=.36)$, phobic anxiety consisted of five items $(\alpha=.82)$, paranoid ideation consisted of five items $(\alpha=.69)$, and psychoticism consisted of five items $(\alpha=.46)$. As the internal consistency ratings for the hostility and psychoticism subscales were below .60, these subscale scores were not included in analyses. The scale as a whole yielded a broadband global severity index, which was then converted to a t-score. The reported internal reliability for the index (based on Cronbach's alpha) is between .70 and .85 (Derogatis, 2004). For the current study, the internal reliability was $\alpha=.92$

Maternal sleep diary. (Appendix B). The Infant Care Diary (ICD) created by Karraker \& Cottrell (2002) was used to assess infant sleep for three days and nights. Mothers marked each 15-minute interval during which the infant slept. From this measure the infant's length and frequency of nighttime awakenings and daytime naps were calculated. Mothers also recorded crying behavior, including frequency and duration of crying. Mothers were also asked to record their own bed time, frequency and estimated length of sleep interruption, time of awakening, frequency of spontaneous checking on the infants, and morning alertness (Dennis \& Ross, 2005; 
Karraker \& Cottrell, 2002). Mothers also reported bedtime and other sleeping practices (e.g., cosleeping, breast-feeding, putting infant in bed awake or asleep).

This method is similar to Richman's (1981) sleep diary. The following infant sleep parameters were derived from this measure: frequency of waking (number of times per night), total time awake (per night), average awake time (per night-time waking), total night sleep per night, frequency of naps per day, average length of naps, total daytime sleep per day, total sleep per 24-hour period, and amount of time spent co-sleeping (if any) per night.

A night waking was determined as any 15-minute interval that the infant was awake after having been asleep for at least one hour, followed by another extended period of sleep in the evening (i.e., after 7:00pm). These night wakings were then counted (frequency), the total time awake was summed (per night) by multiplying the frequency by 15 minutes, and then an average length of the wakings was calculated by dividing the total time awake by the frequency of night wakings. Total sleep time was determined by summing the time the infant was asleep, not including the time the infant was awake. Frequency of naps was determined by counting intervals that the infant was reported as asleep during the day. The average length of naps was then calculated by taking the total daytime sleep per day and dividing it by the number of naps per day. The total sleep per 24-hour period was then calculated by summing the total night sleep and the total daytime sleep. It is important to note that all sleep measures were calculated to reflect the average amount of sleep per day (24-hours). Finally, amount of time co-sleeping appeared to be difficult for mothers to remember to report. Therefore, co-sleeping was determined by a simple yes or no question at the end of the sleep diary that asked the mother if she co-slept with her infant during the three night period. 
Richman's diary as well as the ICD exhibited sufficient reliability and validity in previous research (Karraker \& Cottrell, 2002; Richman, 1981). Specifically, such diaries have been found to be an accurate measure of infant sleep and nocturnal behavior and generally correlate highly with other objective measures of infant sleep (e.g., video somnography,actigraphy) (Hall, Saunders, Clauson, Carty, \& Janssen, 2006; Minde, Popiel, Leos, Falkner, Parker, \& Handley-Derry, 1993).

Maternal cognitions. (Appendix C). Maternal perceptions and sleep-related cognitions were assessed using the Maternal Cognitions about Infant Sleep Questionnaire (MCISQ; Morrell, 1999). The MCISQ is a 20-item measure [each item scored from strongly agree (5) to strongly disagree (0)] that assesses cognitions that mothers have about their infants' sleep. The measure was scored by creating mean scores on five subscales: limit setting, anger, feeding, safety, and doubt. High scores represent negative concerns and doubts on all subscales. The limit setting subscale consisted of five items $(\alpha=.70)$ and reflected endorsement of items associated with difficulties in setting limits or resisting the infant's demands. Another subscale assessed anger-related maternal cognitions, with five items on the scale $(\alpha=.63)$ reflecting negative feelings toward the infant. The feeding subscale contained three items $(\alpha=.41)$ relating to concerns about feeding during the night. The safety subscale consisted of two items $(\alpha=.45)$ and reflected maternal cognitions associated with concern about the infant's safety during the night. Finally, the doubt subscale contained five items $(\alpha=.52)$ concerning thoughts about parental competency related to their infant's sleep (Morrell). The MCISQ included items such as, "I should be getting up during the night to check that my child is still all right." The reported internal reliability (based on Cronbach's alpha) is .82 for the entire measure (Morrell) and .76 for the overall score for this sample. 


\section{Maternal sleep interpretations. The Infant Sleep Vignettes Interpretation Scale (ISVIS)}

(Appendix D) was also utilized to assess maternal cognitions about infant sleep in hypothetical situations. The ISVIS is comprised of 14 vignettes, each describing a different infant sleep problem. The parent was then asked to rate (on a 6-point Likert scale) her agreement with different interpretations and solutions to approaching the problem (Sadeh et al., 2007). For each vignette mothers rated the extent to which they thought the situation was related to distress (i.e., the infant is distressed and the parent should directly soothe the infant) $(\alpha=.95)$, limits (i.e., the infant should learn self-soothing with minimal parental intervention) $(\alpha=.96)$, and temperament (i.e., regardless of what parents do the sleep problem is related to the infant's temperament) $(\alpha=.95)$. The ratings for each of these three interpretations were then summed, with higher scores representing stronger maternal agreement with each of the three categories. The reported internal consistency (based on Cronbach's alpha) is .90 or above for each of the three scales (Sadeh et al., 2007).

Vulnerable Child Scale (VCS; Perrin, West, \& Culley, 1989). (Appendix E).To assess whether or not mothers of premature infants viewed their infants as more vulnerable than did full-term infant mothers, participants completed the VCS. This scale consisted of 16 items (e.g., In general, my infant seems less healthy than other children of the same age). The mother rated each statement as definitely true, mostly true, mostly false, or definitely false with regard to her own infant (Perrin, West, \& Culley, 1989). Scores were calculated by reverse scoring items as appropriate and then summing all of the items with the scale yielding an acceptable internal consistency $(\alpha=.75)$. Scores ranged from 16 to 64 with lower scores representing a maternal belief of greater infant vulnerability (Perrin, et al., 1989). 


\section{Infant developmental status. The Bayley Scales of Infant and Toddler Development}

(BSID-III) were used to assess the infants' developmental status (Bayley, 2006). The assessment consisted of a series of items that are administered to the infant and other items that are obtained via incidental observations (Bayley, 2006). The BSID-III assesses infant cognitive, language, and motor development. The cognitive scale includes items that assess sensorimotor development, exploration, and manipulation. The language scale includes items that assess both receptive (e.g., preverbal behaviors) and expressive (e.g., babbling, gesturing) communication skills. Finally, the motor scale assesses both fine (e.g., prehension) and gross (e.g., movement of the arms and body) motor abilities. The reported reliability of the Bayley is excellent ( $\alpha \geq .84)$, for each of the subscales (Bayley, 2006).

For each of the areas of development represented on the Bayley, items were selected based on the ability of average infants of a particular age to perform items. Therefore, items administered were selected for infants from 4 months and 16 days old to 10 months and 30 days on the cognitive, fine motor, and gross motor subscales. For the language scale items administered were designed for infants from 4 months and 16 days to 13 months and 15 days. The reason for these selections was to allow participants to be presented with items that ranged from easy to difficult; thus, the infant would be able to pass some of the items, but not all of the items. Typically, a composite score would be calculated based on the number of items passed. However, for purposes of this study a composite score was not calculated as the complete scale was not administered to identify ceiling and floor performance. As all infants were administered the same set of items, and the number of correct items was determined for each infant.

Maternal expectations. (Appendix F). The Bayley Expectations Questionnaire created by Karraker (2002) was used to assess mothers' expectations for their infant's performance prior to 
the administration of the BSID-III. For each item, the mother was asked to predict whether or not her infant would be able to perform the action described. Mothers were instructed that if they did not understand an item from the description, they should ask the primary investigator for further explanation or a demonstration of the item (Karraker, 2002). Each item corresponded to the items from the BSID-III described in more detail above. The number of items the mother expected her infant to pass and the number of items the mother expected her infant to fail on the expectations questionnaire were totaled. Next, the number of items the mother indicated her infant would fail and the number of those items the infant actually passed was totaled. Next, the number of items the mother indicated that her infant would pass and the number of those items that the infant actually failed was totaled. Finally, the number of items the mother indicated that her infant would fail and the number of those items that the infant actually did fail was totaled.

Maternal overestimation and underestimation, scores were also calculated based on these totals and the total number of items administered from the BSID-III (Karraker, Atkins, Coleman, \& Cottrell, 2002). Maternal underestimation was calculated by dividing the total number of items the mother reported her infant would fail, but that the infant actually passed, by the total number of items the infant actually passed. Maternal overestimation was calculated by dividing the total number of items the mother reported her infant would pass, but that the infant actually failed, by the total number of items the infant actually failed.

Prematurity stereotyping. (Appendix G). The Stern-Karraker Infant Stereotyping Scale (S-KISS) (Stern \& Karraker, 1990) allowed participants to rate the behavioral, social, cognitive, physical potency, and physical characteristics of the four infants viewed via video. Prior to viewing each video segment, the participant read a vignette that described the infant as male or female and as having been born at full-term or prematurely. The S-KISS consisted of 18 7-point 
adjective scales (e.g., happy/sad, attentive/inattentive, strong/weak) followed by questions regarding toy choice and manipulation check questions. The order of the vignettes and video presentation were counterbalanced in order to allow for assessment and statistical control of order effects. Several items on the measure were then reverse coded. Next, to create an overall prematurity stereotyping score the 18 items were summed and an average rating was calculated separately for the labeled full-term and labeled premature infants viewed. Previous studies using the S-KISS have reported internal consistencies (based on Cronbach's alpha) ranging from .60 to .81 (Stern, Karraker, McIntosh, Moritzen, \& Olexa, 2006; Stern \& Karraker, 1990). For the current sample the internal consistency was acceptable. Specifically, reliability for the first infant viewed was $\alpha=.60$, for the second infant viewed $\alpha=.63$, for the third infant viewed $\alpha=.50$, and for the fourth infant viewed $\alpha=.55$. 


\section{Preliminary Analyses}

A power analysis (G*Power 3; Faul, Erdfelder, Lang, \& Buchner, 2007), utilizing methods outlined by Cohen (1988) was conducted and, using a power criterion of .80, it was determined that a sample of 27 infants and mothers in each group would be adequate to detect a medium effect size in this study for t-tests, analysis of variance, multivariate analysis of variance, and chi-square (based on previous research). According to Cohen (1992), .20 is a small effect size, .50 is a medium effect size, and .80 is a large effect size.

In total, data for 27 late-preterm and 27 full-term infants and their mothers were included in data analysis. In order to combat missing data, the primary investigator reviewed questionnaires prior to compensating participants. If missing data existed, participants were asked if the item was intentionally left blank. Missing data was minimal with the majority of participants omitting no items. The data were initially explored for the presence of outliers. Outliers were identified as values falling outside a box and whisker plot (Branstetter \& Furman, 2005). The following variables contained outliers: (1) VCS total score (one outlier); (2) MCISQ setting limits (three outliers), anger (one outlier), and feeding (one outlier) subscales; and (3) SKISS (one outlier). As recommended by Branstetter and Furman (2005), outliers were recoded by adding or subtracting 2.36 times the standard deviation from the mean. Analyses were then conducted using both the original and trimmed data. Results did not differ based on which data were used, thus, all analyses were conducted on the original, untrimmed data.

In order to meet assumptions for the proposed analyses (i.e., ANOVA, MANOVA) normality of the major variables was investigated by converting skewness $\left(\mathrm{Z}_{\text {Skewness }}=\right.$ Skewness/S.E. $)$ and kurtosis $\left(\mathrm{Z}_{\text {Kurtosis }}=\right.$ Kurtosis $/ S$.E. $)$ values into z-scores. As recommended by 
Field (2009), Z-score values greater than 2.58 were considered to be an indicator of non-normal data. Of all the major study variables, the anger subscale of the MCISQ was positively skewed and the feeding subscale was positively skewed and leptokurtic. In order to correct these violations of normality, the log transformation was used as it is recommended for positively skewed data (Field, 2009). In both cases, the data transformations corrected any violations of normality. All analyses were conducted using both the MCISQ subscales transformed and original data. The results did not differ based on which variables were utilized; therefore, all analyses are reported based on the untransformed data.

The final assumption, homogeneity of variance, was tested using the Explore function in SPSS v.18. Results indicated that for all major study variables the variances were equal except for the following: (1) VCS total score, $F(1,49)=11.9, p<.01$, (2) the MCISQ anger subscale, $F(1,49)=9.74, p<.01,(3)$ the MCISQ feeding subscale, $F(1,49)=5.10, p=.03$, and (4) the MCISQ total score, $F(1,49)=5.16, p=.03$. However, when the log transformation was applied the homogeneity of variance assumption was met. Analyses were conducted with the transformed and untransformed data. As results did not differ, all subsequent analyses used the untransformed data.

\section{Descriptive Statistics}

Demographic characteristics of this sample are presented in Table 2. The majority of infants and their mothers were Caucasian. At the time of study completion the mothers of the late-preterm infants ranged from 23 to 40 years of age and the mothers of the full-term infants ranged from 26 to 40 years of age. The majority of participants reported that they were married. Typically, participants reported having completed high school or obtained a general education 
diploma and approximately half of each sample had completed a college degree. The sample was also nearly evenly split between stay-at-home mothers and mothers who were employed at least part-time.

As can also be seen in Table 2, mothers differed in having help caring for their infant at night with more of the late-preterm infant mothers reporting having help caring for their infant at night than did the full-term infant mothers. Predominately their husband or partner was the person who helped care for the infant at night.

Medical and anthropomorphic measures for this sample are reported in Tables 3 and 4. Mothers differed on type of delivery with the late-preterm infant mothers reporting that the majority of their deliveries were Caesarean and the full-term infant mothers reporting that the majority of their deliveries were vaginal. Late-preterm infant mothers also reported significantly more problems during pregnancy including: preeclampsia, gestational diabetes, placental abruption, and premature labor. Significantly more late-preterm infants had problems at birth than did the full-term infants. Maternal report also indicated that $22 \%$ of the late-preterm infants were reported as small for gestational age, but all of the full-term infants were reported as appropriate size for their gestational age.

The two groups differed in infant gestational age, as would be expected. The gestational ages of the late-preterm infants ranged from 32 to 36 weeks. Conversely, the gestational ages of the full-term infants ranged from 38 to 40 weeks. Following birth, the late-preterm infants were in the hospital significantly longer than the full-term infants. Late-preterm infants' length of stay in the hospital varied broadly (based on illness severity at time of birth, which varied among 
participants) from 2 to 63 days, whereas the full-term infants were only in the hospital from 2 to 3 days.

Feeding patterns of this sample are presented in Table 4. At the time of the study the majority of the infants were being bottle fed and eating some solid foods. Mothers also reported information on reflux diagnosis as it can impact the infants' feeding style and nutritional intake. At the time of the study $67 \%$ of late-preterm infants had been diagnosed with reflux.

Finally, the infant groups did not differ on their current weight, length, or head circumference. Late-preterm infants at the time of the study weighed between 4.70 and 10.34 kilograms, their length ranged from 21 to 29 inches, and their head circumference ranged from 14.00 to 19.50 inches. Full-term infants at the time of the study weighed between 5.19 and 9.70 kilograms, their length ranged from 19 to 29 inches, and their head circumference ranged from 13.75 to 18.50 inches.

Mothers also reported on their history of depression prior to, during, and after pregnancy (see Table 5). The only significant difference between groups was that prior to pregnancy more late-preterm infant mothers (56\%) were diagnosed by a professional with depression than fullterm infant mothers (33\%). However, as can be seen in Table 6, at the time of the study depression scores were significantly higher for the full-term infant mothers than the late-preterm infant mothers.

\section{Major Analyses}

\section{Hypothesis 1 a}

Late-preterm infants will awaken more frequently at night than full-term infants. 
Hypothesis $1 b$

Late-preterm infants will spend less time asleep at night than full-term infants.

Hypothesis1c

Late-preterm infants will take more frequent naps during the day than full-term infants.

Hypothesis $1 d$

Late-preterm infants will be more likely to signal to mothers by crying when they awaken at night than full-term infants.

For Hypotheses 1a-1d separate univariate ANOVAs were conducted allowing for direct tests of the individual hypotheses. Results indicated that there was a significant difference between the groups in total time napping per day, $F(1,52)=4.43, p=.04, \eta_{p}^{2}=0.14$. On average the late-preterm infants spent more time asleep during the day $(M=2.27$ hours per day, $S D=1.24)$ than did the full-term infants $(M=1.70$ hours per day, $S D=0.76)$.

Hypothesis $2 a$

Mothers of late-preterm infants will view their infants as more vulnerable than mothers of full-term infants. A one-way analysis of variance was conducted to determine if mothers of late-preterm infants viewed their infants as more vulnerable than mothers of full-term infants. The independent variable was birth status (late-preterm and full-term). The dependent variable was total score on the VCS. Descriptive statistics are reported in Table 9. Results indicated that there was not a significant difference between late-preterm and full-term infant mothers in their perception of infant vulnerability, $F(1,52)=0.51, p=.47, \eta_{\mathrm{p}}^{2}=0.01$. 
Hypothesis $2 b$

Mothers of late-preterm infants will report more doubt, safety, and anger cognitions than mothers of full-term infants. A multivariate analysis of variance was conducted to determine if mothers of late-preterm infants reported cognitions associated with poorer infant sleep than mothers of full-term infants. The independent variable was birth status (late-preterm and fullterm). The dependent variables were the doubt, safety, limit setting, feeding, and anger cognition scores of the MCISQ. Using Wilks's statistic, there was a significant multivariate effect of birth status, $\lambda=0.70, F(3,49)=2.67, p=0.05, \eta_{\mathrm{p}}^{2}=0.14$.

Investigation of follow-up univariate ANOVAs revealed that there were significant group differences in doubt, $F(1,51)=4.64, p=.03$ and feeding, $F(1,51)=7.31, p<.01$ cognitions reported by mothers. Descriptive statistics are reported in Table 9. Full-term infant mothers reported more intense doubt and feeding cognitions than did late-preterm infant mothers.

\section{Hypothesis $2 c$}

Mothers of late-preterm infants will be more vigilant at night than mothers of full-term infants. A chi-square analysis was conducted to determine if mothers of late-preterm infants were more vigilant at night than mothers of full-term infants. For this analysis the dependent variable was whether or not the mother reported checking on the infant at night. Results indicated that late-preterm infant mothers were more likely to report that they spontaneously checked on their infants than did full-term infant mothers, $\chi^{2}(1, \mathrm{~N}=54)=12, p<.01$. Specifically, 15 late-preterm infant mothers reported spontaneously checking on their infant at least twice during the 3-night period as compared to only 3 full-term infant mothers. 
Hypothesis $2 d$

Mothers of late-preterm infants will more frequently engage in sleeping practices that have been previously shown to promote night waking (e.g., co-sleeping, breast-feeding, vigilance, putting infant in bed asleep) than will mothers of full-term infants. Separate chi-square analyses were conducted for each of these behaviors, which were reported by mothers as yes/no responses. Results indicated that there were few co-sleepers in the total sample (11 co-sleepers vs. 43 non co-sleepers). Of those who did co-sleep significantly more full-term infant mothers (9) co-slept than late preterm infant mothers (2), $p=.04$, Fisher's Exact Test. There was not a significant difference in breast-feeding practices between the groups of mothers $\left(\chi^{2}(1, N=54)=\right.$ $1.94, p=.58$.). Finally, there was not a significant difference between groups in the reporting of putting the infant to bed asleep $\left(\chi^{2}(1, \mathrm{~N}=54)=0.09, p=.77\right.$. $)$

Hypothesis $3 a$

Mothers of late-preterm infants will underestimate (i.e., expect the infant to fail more items than they pass) their infant's performance on the Bayley Scales of Infant and Toddler Development as compared to mothers of full-term infants. A one-way analysis of variance was conducted to determine if mothers of late-preterm infants underestimated their infant's performance on the BSID-III more than did mothers of full-term infants. The independent variable was birth status (late-preterm and full-term). The dependent variable was mothers' calculated underestimation scores from the Bayley Expectations Questionnaire (Karraker, 2002). Results indicated that mothers of late-preterm infants did not significantly underestimate their infant's performance on the Bayley Scales of Infant and Toddler Development as compared to mothers of full-term infants $(F(1,53)=0.95, p=0.34)$. See Table 8 . 
Hypothesis $4 a$

Mothers of late-preterm and full-term infants will view unfamiliar infants labeled as premature more negatively than unfamiliar infants labeled as full-term. A one-way analysis of variance was conducted to determine if mothers of late-preterm and full-term infants viewed unfamiliar infants labeled as premature more negatively than those infants labeled as full-term. The within-subjects independent variable was premature versus full-term label (late-preterm and full-term). The dependent variable was mothers' average ratings of full-term and premature labeled infants. Results indicated that late-preterm and full-term mothers did not view unfamiliar infants labels as premature more negatively than unfamiliar infants labeled as full-term, $F(1,50)$ $=0.33, p=0.78, \eta_{\mathrm{p}}^{2}=0.02$.

Additional analyses were also conducted to determine if there were differences between the two groups of mothers. The independent variable was birth status (late-preterm and full-term. The dependent variable was mothers' average ratings of full-term and premature labeled infants. Results indicated that late-preterm and full-term infant mothers viewed premature infants similarly, $\mathrm{F}(1,50)=0.54, \mathrm{p}=.54, \eta_{\mathrm{p}}^{2}=0.03$. Conversely, mothers rated the full-term infants differently, $F(1,50)=4.31, p=.04, \eta_{p}^{2}=0.12$. As can be seen in Table 9 on average late-preterm infant mothers rated full-term infants less positively than did full-term infant mothers.

Hypothesis $4 b$

Late-preterm infant mothers who engage in prematurity stereotyping will have infants who demonstrate poorer sleep patterns than late-preterm infant mothers who do not engage in prematurity stereotyping. Separate univariate ANOVAs revealed that there was a significant difference in total sleep time in a 24-hour day, $F(1,23)=3.74, p=.04, \eta_{p}^{2}=0.18$, with those 
infants whose mothers participate in prematurity stereotyping sleeping more than those infants whose mothers do not participate in prematurity stereotyping. 


\section{Discussion}

The purpose of the current study was to investigate potential differences in late-preterm and full-term infant sleep and any psychosocial factors (i.e., maternal sleep-related cognitions and nocturnal behaviors) that may contribute to these differences. Few studies have investigated the relations among infant sleep behavior, mothers' cognitions about infant sleep, and mothers' sleep-related behaviors in mothers of full-term and late-preterm infants. Information about these relations might contribute to an understanding of why late-preterm infants might sleep less well than full-term infants.

\section{Late-preterm and full-term infant sleep}

It was hypothesized that late-preterm infants would sleep less well than full-term infants at 6 months corrected age. Specifically, it was predicted that late-preterm infants would awaken more frequently at night and signal to their mothers by crying, spend less time asleep at night, and take more frequent naps during the day. Contrary to predictions, late-preterm infants and full-term infants in the current study were similar in their sleeping behaviors. Evidence is accumulating that preterm and full-term infants do not differ as drastically in their development of sleep/wake patterns as once thought (Iglowstein, Hajnal, Molinari, Largo, \& Jenni, 2006). For example, Iglowstein and colleagues (2006) longitudinally investigated sleeping patterns in preterm children (mean gestational age 34.1) from birth through ten years of age. Sleeping patterns were assessed via maternal report and of particular interest were sleep duration, cosleeping behaviors, night wakings, and bedtime routines. Results illustrated no significant differences between the two groups. The authors suggest that parent-child interaction may be 
more important than prematurity in shaping sleep/wake behaviors in these children (Iglowstein et al., 2006).

Conversely, while the two groups were similar in their napping frequency, the lengths of those naps were significantly different with late-preterm infants sleeping on average an hour more per day than full-term infants. To date there is little research about the nap taking behaviors of infants. Some research has found that premature infants tend to exhibit less effective selfregulation abilities than full-term infants (Davis \& Burns, 2001). Premature infants have been observed to sleep less well at night and display more sleep/wake transitions than full-term infants (Ju et al., 1991; Keener, Zeanah, \& Anders, 1988). Thus, it could be postulated that while the frequency of night waking and the amount of time spent asleep is not significantly different between the two groups the quality of the sleep that the late-preterm infants are receiving is less than that of the full-term infants. Thus, to compensate for lower quality sleep the late-preterm infants are taking longer naps during the day.

Researchers from the CHIME Group (CHIME Study Group, 2006) argue that when investigating sleep patterns in premature infants the impact of premature birth on both the mother and the infant, along with the use of oxygen support (e.g., mechanical ventilation) combined with the protracted extrauterine exposure need to be taken into account. The authors go on to argue that these characteristics will either place the late preterm infant at an advantage or a disadvantage that could result in advances or delays in this development (CHIME Study Group, 2006). For example, Scher (1997) reported that one group of premature infants (44 weeks postmenstrual age) exhibited longer uninterrupted bouts of quiet sleep than did their age matched counterparts. Thus, it could be hypothesized that in the current sample differences in the amount of active and quiet sleep impact the amount of sleep the late-preterm infants are getting during 
the day. This more objective assessment of sleep would also allow for the investigation of the effects of napping behavior on night-time sleep and sleep efficiency.

\section{Maternal perceptions of late-preterm and full-term infant sleep}

Mothers' perceptions of their infants' sleep were also investigated using the previously mentioned MCISQ. Of particular interest in this study were significant group differences in the doubt, safety, and anger cognitions. Results indicated that mothers differed in their endorsement of doubt and feeding cognitions, whereas, mother's endorsement of safety and anger cognitions were similar between groups. Full-term infant mothers reported more intense doubt and feeding cognitions than the late-preterm infant mothers. Previous research has found that maternal beliefs, expectations, perceptions, and ultimately behavior related to infant sleep is governed by a myriad of factors, including environmental factors, personal history, personality, and chief among them psychopathology (Sadeh, Tikotzky, \& Scher, 2009). The psychopathology that has received the most attention is maternal depression (Armitage, Flynn, Hoffmann, Vazquez, Lopez, \& Marcus, 2009; Bayer, Hiscock, Hampton, \& Wake, 2006). Indeed, post-natal depression affects $10-15 \%$ of women in the first year post-partum (Dennis \& Ross, 2005). For the current sample, a larger proportion of late-preterm infant mothers had reported being diagnosed by a professional for depression prior to and since pregnancy. Of those a large majority reported taking prescription medications. For the full-term infant mothers, results were similar, but with one striking difference and that was the full-term infant mothers scored higher on the depression subscale of the Brief Symptom Inventory (BSI) than did the late-preterm infant mothers. The full-term infant mothers more strongly endorsed the items on the depression subscale than did the late-preterm infant mothers. Thus, it could be that these depressive 
symptoms are distorting how the full-term infant mother thinks about infant sleep, leading to concerns over feeding and doubting infant sleep-related parenting.

Indeed, exploratory analyses indicated that maternal depression scores were associated with the feeding $(r=.40, p<.01)$, but not doubt $(r=.18, p=.20)$ subscales of the MCISQ. There are three items on the feeding subscale of the MCISQ: "When my child wakes at night, I think I might not have fed him/her enough during the day, My child might go hungry if I don't give him/her a feed at night, and If I give up feeding at night, then he/she will never sleep." Caregiving activities, especially feeding, tend to be most impacted by maternal postpartum depression. Research has found that depressed mothers tend to report lower satisfaction and efficacy with breastfeeding as compared to controls and also are more likely to discontinue breastfeeding by 16 weeks postpartum (Dennis \& McQueen, 2007; McLearn, Minkovitz, Strobino, Marks, \& Hou, 2006). Thus, it could be posited that the current sample of depressed mothers are endorsing a behavioral profile characterized by heightened sensitivity to their infant feeding issues, especially at 6 months when the infant is transitioning to the combination of milk and solid foods. Conversely, the doubt subscale is comprised of five items covering varied issues, including general parental competence and bedtime routines (e.g., I am able to let my child sleep on his/her own) that may not be as salient to the depressed mother as the issues surrounding feeding.

In addition, results indicated that mothers of late-preterm infants were more vigilant at night than were mothers of full-term infants. Specifically, 15 of the late-preterm infant mothers reported checking on their infant (unrelated to infant signaling) at least twice during the 3-night period. Because mothers of premature infants know that their infants may be at a higher risk for SIDS they may become hypersensitive to their infant's state changes (Horne et al., 2001). Thus, 
mothers may become highly attuned to any infant restlessness and intervene by checking on the infant. Hospitalization of a preterm infant in the NICU often leads to severe distress in the mother, as she worries about infant survival and the loss and reorganization of the maternal role (Holditch-Davis, Bartlett, \& Miles, 2003). For the current sample, the late-preterm infants spent on average a little over 2 weeks in the hospital, some with breathing support, as compared to only 2.5 days on average for the full-term infants. Some research has argued that this stress resembles that of individuals suffering from posttraumatic stress disorder (PTSD) (HolditchDavis, Bartlett, \& Miles, 2003). PTSD is typically experienced by victims of a traumatic event and is comprised of three symptoms: re-experiencing of the trauma (e.g., flashbacks), avoidance of any reminders, and increased arousal and anxiety (Holditch-Davis, Bartlett, \& Miles, 2003). This latter component of increased arousal could be leading to the hypervigilence of the mothers of late-preterm infants and is manifested behaviorally by spontaneous checking on the infant at night.

Indeed, previous research has found that as many as $30 \%$ of premature infant mothers could meet criteria for Acute Stress Disorder (ASD), the antecedent to PTSD (Shaw, Deblois, Ikuta, Ginzburg, Fleisher, \& Koopman, 2006). In Shaw et al.’s study, mothers and fathers reported on their stress levels one month after their infant was hospitalized in the NICU. The most interesting finding was that the ASD symptoms were not found to be associated with infant's current medical status, length of stay in the NICU, or gestational age (Shaw et al., 2006). For the current study, it may be that even though the late-preterm infant has been out of the hospital for at least 5 months, there is still residual stress that the mother is experiencing, leading to heightened arousal, and ultimately the hypervigilence (i.e., spontaneous checking) that was seen in the current sample. 
Maternal nocturnal behaviors and late-preterm and full-term infant sleep

It was also hypothesized that mothers of late-preterm infants would be more likely than mothers of full-term infants to participate in sleeping practices (e.g., cosleeping, putting the infant to bed asleep) that had previously been shown to relate to more infant night waking. For example, past research has found that the use of physical comforting is predictive of continual infant night waking (Morrell, 1999). Results indicated that this was not the case and that the groups were similar in their tendencies to participate in these types of behaviors. For example, cosleeping was actually low in the entire sample, with only $20 \%$ of the sample participating in cosleeping. This low frequency of cosleeping behavior could be related to the fact that the majority of the mothers were no longer breast-feeding, but rather bottle-feeding supplemented with solids. Thus, the lower frequency of breast-feeding could be related to the low frequency of co-sleeping practices as well. Indeed, research has found that breast-feeding mothers are three times more likely to co-sleep than mothers who are bottle-feeding (McCoy, Hunt, Lesko, Vezina, Corwin, Willinger, Hoffman, \& Mitchell, 2004).

\section{Maternal perceptions and expectations}

It was also predicted that mothers of late-preterm infants would view their infants as more vulnerable than mothers of full-term infants. Results indicated that this was not the case and that mothers of both groups viewed their infants similarly. Support for this hypothesis was drawn from seminal research by Perrin, West, and Culley and others that found that mothers of medically ill children did view their infants and children as vulnerable even with medical evidence to the contrary. In this early study, the sample consisted of infants born prematurely and at less than 1500 grams (Perrin, West, \& Culley, 1988). Conversely, in the current study 
participants were premature infants born between 32 and 37 weeks gestation and only $26 \%$ of the late-premature infants were reported as small for gestational age (SGA). Also at the time of the study the infants were all healthy and normal weight, with no major medical illnesses. As a result of these characteristics at the time of the study the late-preterm infant mothers did not perceive their infants as more vulnerable compared to the full-term infant mothers. However, it is important to note that even though the differences between groups was not significant, latepreterm infant mothers' scores on the Vulnerable Child Scale were still lower than the full-term infant mother scores indicating some perception of infant vulnerability. Thus, if the sample size had been larger the difference between late-preterm and full-term infant mothers may have been significant.

It was also hypothesized that this perception of vulnerability would lead late-preterm infant mothers to underestimate their infants' performance on the Bayley Scales of Infant and Toddler Development (Bayley, 2006). Research has supported the idea that parents hold expectations or goals about what their infant or child should be able to do developmentally (van Beek, Genta, Costabile, \& Sansavini, 2006). If these expectations are unrealistic it may lead to disappointment and negative perceptions of the infant (van Beek, Genta, Costabie, \& Sansavini, 2006). Research postulates that parental expectations may be altered when an infant is born prematurely. For example, research has shown that mothers of premature infants (born at less than 1500 grams) view their child as more vulnerable (i.e., more susceptible to health problems) than do mothers of full-term infants (Perrin, West, \& Culley, 1988). As a result of this possible view of the late-preterm infant as vulnerable less favorable developmental outcomes may be anticipated by the mother. Results indicated that both late-preterm and full-term infant mothers were similar in their underestimations of their infants' performance on the Bayley. This finding 
is in line with other research that has found that late-preterm infant mothers and full-term infant mothers do not differ radically in their expectations for their infant's development (Davis, Edwards, Mohay, \& Wollin, 2003). In fact, some studies have found that premature infant mothers have positive expectations for their infants and these positive expectations have been associated with lower maternal depression and anxiety scores (Padovani, Linhares, Pinto, Duarte, \& Martinez, 2008). It could be posited that the positive expectations and lack of a vulnerable perception of the current sample of late-preterm infant mothers is a type of adaptive, protective mechanism for the mental health of the mother and the healthy development of the infant.

Maternal expectations and perceptions were also investigated via the assessment of prematurity stereotyping in the sample. It was hypothesized that both full-term and late-preterm infant mothers would rate unfamiliar infants labeled as premature less positively than infants labeled as full-term. Results indicated that this was not the case and that both groups of mothers rated the premature labeled infants similarly. Interestingly, additional analyses indicated between-group differences with late-preterm infant mothers rating full-term infants less positively than did full-term infant mothers. One explanation for this finding is that the latepreterm infants in this sample are relatively low-risk, meaning that since birth there had not been any major medical complications (with the exception of one infant with a heart defect). In fact, the majority of the late-preterm sample had not been to the doctor outside of routine well-baby visits and had not had any re-hospitalizations since discharge from the NICU. Ingleby and Tanke (1995) would argue that high-risk preterm infants (born at less than 32 weeks gestation and/or less than 1500 grams) will most definitely exhibit varying characteristics as a result of their medical complications. Thus, it could be that the prematurity stereotyping phenomenon would only exist for mothers of medically ill premature infants (Ingleby \& Tanke, 1995). 
The current findings actually contradict earlier work of Stern and colleagues (2000) that found, in a sample of healthy pre-term infants at 6-months corrected age, that mothers rated the premature infants less favorably than the full-term infants, even selecting a more immature toy for the infant to play with. In this study, there was no such indication of this stereotype. It could be that the positive health outcomes of their infant since discharge overrode any vulnerable child perception of their own or unfamiliar infants. Additionally, the reverse of this phenomenon was found where late-preterm infant mothers tended to rate the full-term infants less positively than did the full-term infant mothers. It could be that the late-preterm infant mothers' recent experience of prematurity and associated medical complications created a negative perception of full-term infants and a positive perception of premature infants.

It was also hypothesized that prematurity stereotyping would impact infant sleep with late-preterm infant mothers who engage in prematurity stereotyping having infants who slept less well than those late-preterm infant mothers who did not participate in prematurity stereotyping. Prior research has found that those mothers of premature infants who engaged in prematurity stereotyping had more negative interactions with their own infant than mothers who did not (Stern et al., 2006). Results indicated that this was indeed the case with mothers who engaged in prematurity stereotyping having infants who slept more per 24 hours than did infants whose mothers did not participate in prematurity stereotyping. However, if a mother perceives an unfamiliar prematurely labeled infant more negatively than an unfamiliar full-term labeled infant it could be assumed that she holds negative beliefs about premature infants in general, including her own. Therefore, it could be posited that how the mother perceives her infant and her tendency to engage in prematurity stereotyping affected her sleep-related responses to her infant. 
For example, the mother may not have interacted with her infant as much during the day and to dissuade interaction encouraged the infant to take more naps. The increase in daytime sleep for the infant would consequently decrease the amount of interaction that the mother would have to have with her infant. It is also important to note that $37 \%$ of the late-preterm infant mothers had been diagnosed by a professional after pregnancy with depression. Research has reliably found associations between maternal depression and infant outcomes. How infant sleep problems and maternal depression are related (and, in particular, whether one causes the other) is yet to be established. Studies consistently report more depressive symptoms in mothers of poor sleepers than in mothers of good sleepers (Dennis \& Ross, 2005; Goodlin-Jones, Eiben, \& Anders, 1997). So it could be postulated that the maternal depression is in some way impacting the infants' sleep, thus causing them to sleep more in a 24-hour day as compared to those infants whose mothers are not depressed. In an adult sample, current research by Buxton and Marcelli (2010) found that long sleep (more than 7-8 hours per night) was positively associated with obesity, diabetes, hypertension, and cardiovascular disease. Conversely, infants spend the majority of their time asleep, so whether long sleep in infants may in some way impact infant development cannot be determined from the results of the current study.

\section{Summary}

Taken together results of this study indicate that while not extensive, a few sleep differences do exist between late-preterm and full-term infants at 6 months of age, with latepreterm infants sleeping more during the day than full-term infants. However, relations between infant sleep and maternal cognitions and nocturnal behaviors are less clear. The current sample of late-preterm infants did not endorse cognitions nor participate in nocturnal behaviors that had been previously associated with poorer infant sleep patterns. In some cases, full-term infant 
mothers were more likely to report certain cognitions (e.g., doubt) than late-preterm infant mothers. This could be related to the psychopathology that was reported in the current sample of full-term infant mothers, including depression. However, late-preterm infant mothers were more vigilant at night than full-term infant mothers, supporting the idea of a slight maternal expectation of infant vulnerability.

Maternal expectations of premature infants in general were also not different between groups with late-preterm infant mothers actually rating unfamiliar full-term infants less favorably than unfamiliar premature labeled infants. While contradictory to what was hypothesized, the findings are in line with research supporting the idea that positive experiences the mothers have had with their own infants would override any negative beliefs held about premature infants. Finally, maternal expectations of infant development also did not differ as was hypothesized. In fact, mothers in the entire sample tended to be accurate reporters of their infant's developmental abilities.

\section{Limitations and Future Directions}

Results should be interpreted within the context of the limitations of the current study. First, the sample size was small. While a power analysis did indicate sufficient power for the proposed analyses to be conducted, a larger sample would have aided in detecting more nuanced differences in the sleep variables. The smaller sample could also have increased the chances of making a Type II error (Field, 2009). Second, the reporting of infant sleep was based on maternal report, as such diaries have been found to be an accurate measure of infant sleep and nocturnal behavior and generally correlate highly with other objective measures of infant sleep (e.g., video somnography, actigraphy) (Hall, Saunders, Clauson, Carty, \& Janssen, 2006; Minde, Popiel, 
Leos, Falkner, Parker, \& Handley-Derry, 1993). It could also be argued that more differences would have been seen if weekday sleep had been investigated as compared to weekend sleep. Research with adult populations has found that bedtimes and wake times are later on weekends versus weekdays, but findings in infant sleep patterns for weekdays versus weekends is lacking (Monk, Buysse, Rose, Hall, \& Kupfer, 2000). Future research should investigate differences in infant sleep variability from weekdays to weekends. Inclusion of a more objective assessment of sleep (e.g., video somnography) would have also allowed for the assessment of sleep state. Research has previously found differences in the amount of active and quiet sleep between premature and full-term infants (Scher, 1997). These differences could have also been present in this sample; however, a maternal sleep diary would not have been able to capture those differences.

Third, it could also be argued that the age of assessment could have impacted the results of this study. It could be that there are more pronounced differences between full-term and latepreterm infant sleep early in life (e.g., 2 to 4 months post-discharge) and that by 6 months corrected age, the late-preterm infants' central nervous system has continued to develop and the intensity of birth complications has decreased such that any potential differences have diminished. Indeed, previous research suggests that the development of sleep-wake cycles is not only related to gestational age, but also hormonal processes (i.e., melatonin rhythm development), amount of light exposure, and parental interaction (Anders, 1994; Sadeh, 1994). Thus, future research should investigate late-preterm infant sleep at multiple time points, including soon after hospital discharge, in order to tease apart more subtle differences between late-preterm and full-term infants. 
Fourth, the assessment of infant development via the Bayley may have been biased as a result of the researcher not being blind to infant birth status. The researcher may have administered the items differently based on infant characteristics or characteristics of the home environment. Thus, all of the home visits were videotaped and any potential bias could potentially be assessed in the future. However, the assessment of any researcher bias was beyond the scope of the current study. Future studies should utilize multiple raters who are blind to infant birth status, reducing any bias, and enhancing the reliability of the assessment.

Finally, the full-term mothers in this sample demonstrated more psychopathology than the late-preterm infant mothers, potentially impacting the direction of some of the results. One of the reasons that the full-term mothers were different could relate to the fact that the majority (70\%) of mothers were stay-at-home. Some research has found that employment may offer a slight protective factor against depression and anxiety, but results in this area are mixed (McCarten, 2004). Recruitment strategies were also different for the two groups. Late-preterm infant mothers were all recruited at scheduled Well-Baby visits at the Neonatal Follow-Up Clinic, whereas full-term infant mothers were recruited from the community via flyers, newspaper ads, local health fairs, and referrals from other studies. It may be that the more depressed full-term infant mothers may have been more inclined to participate in the study than non-depressed full-term infant mothers. This would make the full-term infant mothers a more self-selected sample than the late-preterm infant mothers. Future studies may benefit from a more balanced recruitment strategy and the use of a structured clinical interview (allowing for the assessment of prior depression and potential associations with infant sleep) and assessment of maternal self-esteem and parenting stress. 


\section{Implications}

The development of sleep is one of the most important and dramatic processes of infancy and early childhood. The development of sleep/wake patterns in premature infants as an area of research is one that is sparse and the results incongruent. Research investigating sleep in latepremature infants is even less available. Thus, while the current study did not yield a wide range of statistically significant results, practically, it is an important first step in understanding the development of sleep patterns in late-premature infants. Furthermore, the lack of differences between the current groups can be viewed as positive findings and clinically significant. In the context of the current study, the infants born slightly premature seem to develop similarly to age matched full-term infants and there is no evidence from this study of cognitive or perceptual issues in the mothers that might interfere with healthy infant development. 


\section{References}

Acebo, C., Sadeh, A., Seifer, R., Tzischinsky, O., Wolfson, A. R., Hafer, A., Carskadon, M.A. (1999). Estimating sleep patterns with activity monitoring in children and adolescents:

How many nights are necessary for reliable measures? Sleep, 22, 95-103.

Adams, S. M., Jones, D. R., Esmail, A., \& Mitchell, E. A. (2004). What affects the age of first sleeping through the night? Journal of Pediatric Child Health, 40, 96-101.

American Academy of Pediatrics' Task Force on Infant Positioning and SIDS (1992).

Positioning and SIDS. Pediatrics, 89, 1120-1126.

Anders, T. F,. \& Taylor, T. R. (1994). Babies and their sleep environment. Children's

Environments, 11, 123-134.

Anders, T. F., \& Keener, M. (1985). Developmental course of nighttime sleep-wake patterns in full-term and premature infants during the first year of life. I. Sleep, 8, 173-192.

Armitage, R., Flynn, H., Hoffmann, R., Vazquez, D., Lopez, J., \& Marcus, S. (2009). Early developmental changes in sleep in infants: The impact of maternal depression. Sleep, 32, 693-696.

Baron, R.M., \& Kenny, D. A. (1986). The moderator-mediator variable distinction in social psychological research: Conceptual, strategic, and statistical considerations. Journal of 
Personality \& Social Psychology, 51, 1173-1182.

Bayer, J. K., Hiscock, H., Hampton, A., \& Wake, M. (2007). Sleep problems in young infants and maternal mental and physical health. Journal of Pediatrics \& Child Health, 43, 66 73.

Brandon, D. H., Holditch-Davis, D., \& Winchester, D. M. (2005). Factors affecting early neurobehavioral and sleep outcomes in preterm infants. Infant Behavior \& Development, 28, 206-219.

Burnham, M. M., Goodlin-Jones, B. L., Gaylor,E.E., \& Anders, T. F. (2002). Nighttime sleep wake patterns and self-soothing from birth to one year of age: A longitudinal intervention study. Journal of Child Psychology \& Psychiatry, 43, 713-725.

Buxton, O. M., \& Marcelli, E. (2010). Short and long sleep are positively associated with obesity, diabetes, hypertension, and cardiovascular disease among adults in the United States. Social Sciences and Medicine, 71, 1027-1036.

Chyi, L. J., Lee, H. C., Hintz, S. R., Gould, J. B., \& Sutcliffe, T. L. (2008). School outcomes of late preterm infants: Special needs and challenges of infants born at 32 to 36 weeks gestation. Journal of Pediatrics, 153, 25-31.

Davis, D. W., \& Burns, B. (2001). Problems of self-regulation: A new way to view deficits in children born prematurely. Issues in Mental Health Nursing, 22, 305-323. 
Davis, L., Edwards, H., Mohay, H., \& Wollin, J. (2003). The impact of very premature birth on the psychological health of mothers. Early Human Development, 73, 61-70.

Davis, B. E., Moon, R. Y., Sachs, H. C., \& Ottolini, M. C. (1998). Effects of sleep position on infant motor development. Pediatrics, 102, 1135-1140.

Derogatis, L., \& Fitzpatrick, M. (2004). The SCL-90-R, the Brief Symptom Inventory (BSI), and the BSI-18. The use of psychological testing for treatment planning and outcomes assessment: Volume 3: Instruments for adults (3rd ed) (pp. 1-41). Mahwah, NJ US: Lawrence Erlbaum Associates Publishers.

DeLeon, C. W., \& Karraker, K. H. (2007). Intrinsic and extrinsic factors associated with night waking in 9-month-old infants. Infant Behavior and Development, 30, 595-605.

Dement, W. C. \& Vaughan, C. (1999). Take age into account. In The promise of sleep (pp. 397418). New York: Dell Publishing.

Dennis, C. L., \& McQueen, K. (2007). Does maternal postpartum depressive symptomatology influence infant feeding outcomes ? Acta Paediatrica, 96, 590-594.

Dennis, C. L. \& Ross, L. (2005). Relationships among infant sleep patterns, maternal fatigue, and development of depressive symptomatology. Birth, 32, 187-193.

Eckerman, C. O., Hsu, H. C., Molitor, A., Leung, E. H. L., \& Goldstein, R. F. (1999). Infant 
arousal in an en-face exchange with a new partner: Effects of prematurity and perinatal risk. Developmental Psychology, 35, 282-293.

Engle, W. A., Tomashek, K. M., Wallman, C., \& the Committee on Fetus and Newborn (2007). “Late-Preterm" infants: A population at risk. Pediatrics, 120, 1390-1401.

Faul, F., Erdfelder, E., Lang, A. G., \& Buchner, A. (2007). G*Power 3: A flexible statistical power analysis program for the social, behavioral, and biomedical sciences. Behavior Research Methods, 39, 175-191.

Field, A. (2009). Discovering statistics using SPSS Third Edition. London, England: Sage Publishing.

Frazier, P. A., Barron, K. E., \& Tix, A. P. (2004). Testing moderator and mediator effects in counseling psychology research. Journal of Counseling Psychology, 51, 115-134.

Gennaro, S. (1988). Postpartum anxiety and depression in mothers of term and preterm infants. Nursing Research, 37, 82-84.

Gossel-Symank, R., Grimmer, I., Korte, J., \& Siegmund,R. (2004). Actigraphic monitoring of the activity-rest behavior of preterm and full-term infants. Chronobiology International, $21,661-671$.

Gottman, J., Katz, L., \& Hooven, C. (1996). Parental meta-emotion philosophy and the emotional life of families: Theoretical models and preliminary data. Journal of Family Psychology, 10, 243-268. 
Hall, W., Saunders, R., Clauson, M., Carty, E., \& Janssen, P. (2006). Effects of an intervention aimed at reducing night waking and signaling in 6- to 12-month-old infants.

Behavioral Sleep Medicine, 4, 242-261.

Hayes, M. J., Roberts S. M., \& Stowe, R. (1996). Early childhood co-sleeping: Parent-child and parent-infant nighttime interactions. Infant Mental Health Journal, 17, 348-357.

Holditch-Davis, D., Bartlett, T. R., \& Miles, M. S. (2003). Posttraumatic stress symptoms in mothers of premature infants. Journal of Obstetrics, Gynecological, \& Neonatal Nursing, $32,161-171$.

Hoppenbrouwers, T., Hodgman, J. E., Rybine, D., Fabrikant, G., Corwin, M., Crowell, D., \& Weese-Mayer, D. E.; CHIME Study Group. (2005). Sleep architecture in term and preterm infants beyond the neonatal period: The influence of gestational age, steroids, and ventilator support. Sleep, 28, 1428-1436.

Horne, R. S. C., Andrew, S., Mitchell, K., Sly, D. J., Carnage, S. M., Chau, B., \& Adamson, T. M. (2001). Apnea of prematurity and arousals from sleep. Early Human Development, 61, 119-133.

Hsieh, S., Cheng, I. C., \& Tsai, L. L. (2007). Immediate error correction process following sleep deprivation. Journal of Sleep Research, 16, 137-147.

Iglowstein, I., Hajnal, B., Molinari, L., Largo, R. H., \& Jenni, O. G. (2006). Sleep behavior in 
preterm children from birth to 10 years: A longitudinal study. Pediatrics, 12, 1691-1693.

Ingersoll, E. W. \& Thoman, E. B. (1999). Sleep/wake states of preterm infants: Stability, developmental change, diurnal variation, and relation with caregiving activity. Child Development, 70, 1-10.

Ju, S. H., Lester, B., Coll, C. G., Oh, W., \& Vohr, B. R. (1991). Maternal perceptions of the sleep patterns of premature infants at seven months corrected age compared to full term infants. Infant Mental Health Journal, 12, 338-346.

Kahn, A., Dan, J., Groswasser, P., Franco, P., \& Sottiaux, M. (1996). Normal sleep architecture in infants and children. Journal of Clinical Neurophysiology, 13, 184-197.

Karraker, K. H., \& Young, M. (2007). Night waking in 6-month-old infants and maternal depressive symptoms. Journal of Applied Developmental Psychology, 28, 493-498.

Karraker, K. H., \& Cottrell, L. (2002). Correlates of nap taking in mothers of young infants. Journal of Sleep Research, 11, 209-212.

Karraker, K. H., \& Evans, S. L., (1996). Adolescent mothers' knowledge of child development and expectations for their own infants. Journal of Youth and Adolescence, 25, 651-666.

Keener, M., Zeanah, C., \& Anders, T. (1988). Infant temperament, sleep organization, and night time parental intervention. Pediatrics, 81, 762-771.

Kelly, M. M. (2006). Primary care issues for the healthy premature infant. Journal of Pediatric 
Health Care, 20, 293-299.

Kline, R. B. (2005). Principles and practice of structural equation modeling. New York, NY: The Guilford Press.

Lau, R. \& Morris C. A. (2003). Stress experiences of parents with premature infants in a special care nursery. Stress and Health, 19, 69-78.

McCarten, J. (2004). Differences in depression, anxiety, self-esteem, and parenting stress between employed and stay-at-home mothers: A meta-analysis [Abstract]. Dissertation Abstracts International, 65, 481.

McCoy, R. C., Hunt, C. E., Lesko,S. M., Vezina, R., Corwin, M. J., Willinger, M., Hoffman, H. J., \& Mitchell, A. A. (2004). Frequency of bed sharing and its relationship to breastfeeding. Journal of Developmental \& Behavioral Pediatrics, 25, 141-149.

McLearn, K. T., Minkovitz, C. S., Strobino, D. M., Marks, E., \& Hou, W. (2006). Maternal depressive symptoms at 2 to 4 months postpartum and early parenting practices. Archives of Pediatric \& Adolescent Medicine, 160, 279-284.

Meyer, E. C., Garcia, T. C., \& Seifer, R. (1995). Psychological distress in mothers of preterm infants. Journal of Developmental \& Behavioral Pediatrics, 16, 412-417.

Middlemiss, W. (2004). Infant sleep: A review of normative and problematic sleep and 
interventions. Early Child Development \& Care, 174, 99-122.

Miller, S. A. (1995). Parents' attributions for their children's behavior. Child Development, 66, 1557-1584.

Minde, K. (2000). Prematurity and serious medical conditions in infancy: Implications for development, behavior, and intervention. Handbook of infant mental health (2nd ed.) (pp. 176-194). New York, NY US: Guilford Press.

Minde, K., Popiel, K., Leos, N., \& Falkner, S. (1993). The evaluation and treatment of sleep disturbances in young children. Journal of Child Psychology and Psychiatry, 34, 521 $-533$.

Mindell, J. A. (1999). Empirically supported treatments in pediatric psychology: Bedtime refusal and night wakings in young children. Journal of Pediatric Psychology, 24, 465-481.

Monk, T. H., Buysse, D. J., Rose, L. R., Hall, J. A., \& Kupfer, D. J. (2000). The sleep of healthy people: A diary study. Chronobiology International, 17, 49-60.

Morrell, J., \& Steele, H. (2003). The role of attachment security, temperament, maternal perception, and care-giving behavior in persistent infant sleep problems. Infant Mental Health Journal, 24, 447-468.

Morrell, J. M. P. (1999). The role of maternal cognitions in infant sleep problems as assessed by a new instrument, the Maternal Cognitions about Infant Sleep Questionnaire. The Journal 
of Child Psychology \& Psychiatry, 40, 247-258.

Mosko, S., Richard, C., McKenna, J,. \& Drummond, S. (1996) Infant sleep architecture during bedsharing and possible implications for SIDS, Sleep, 19, 677-684.

National Institute of Child Health and Human Development Early Child Care Research Network (1999). Chronicity of maternal depressive symptoms, maternal sensitivity, and child functioning at 36 months. Developmental Psychology, 35, 1297-1310.

Olafsen, K. S., Kaaresen, P. I., Handegard, B. H., Ulvund, S. E., Dahl, L. B., \& Ronning, J. A. (2008). Maternal ratings of infant regulatory competence from 6 to 12 months: Influence of perceived stress, birth-weight, and intervention: A randomized control trial. Infant Behavior \& Development, 31, 408-421.

Padovani, F. H. P., Linhares, M. B. M., Pinto, I. D., Duarte, G., \& Martinez, E. (2008). Maternal concepts and expectations regarding a preterm infant. The Spanish Journal of Psychology, 11, 581-592.

Perrin, E. C., West, P. D., \& Culley, B. S. (1989). Is my child normal yet? Correlates of vulnerability. Pediatrics, 83, 355-363.

Pilcher, J. J., \& Huffcutt, A. J. (1996). Effects of sleep deprivation on performance: A meta analysis. Sleep: Journal of Sleep Research \& Sleep Medicine, 19, 318-326. 
Richman, N. (1981). A community survey of characteristics of one to two year-olds with sleep disruptions. Journal of the American Academy of Child Psychiatry, 20, 281-291.

Sadeh, A., Tikotzky, L., \& Scher, A. (2010). Parenting and infant sleep. Sleep Medicine Reviews, 14, 89-96.

Sadeh, A., Flint-Ofir, E., Tirosh, T., Tikotzky, L. (2007). Infant sleep and parental sleep-related cognitions. Journal of Family Psychology, 21, 74-87.

Sadeh, A. (2005). Cognitive-behavioral treatment for childhood sleep disorders. Clinical Psychology Review, 25, 612-628.

Sadeh, A. (1994). Assessment of intervention for infant night waking: Parental reports and activity-based home monitoring. Journal of Consulting and Clinical Psychology, 62, 6368.

Sadeh, A. \& Anders, T. F. (1993). Infant sleep problems: Origins, assessments, interventions. Infant Mental Health Journal, 14, 17-34.

Schaub, K. R., Hunt, C. E., Crowell, D., Golub, H., Smok-Pearsall, S., Palmer, P., Schafer, S., Bak, S., Canteny-Kiser, J., \& O’Bell, R. (2001). Relationship between infant sleep position and motor development in preterm infants. Journal of Developmental and Behavioral Pediatrics, 22, 293-299.

Scher, M. (1997). Neurophysiologic assessment of brain function and maturation: A measure of 
brain dysmaturity in healthy preterm neonates. Pediatric Neurology, 16, 287-295.

Shaw, R. J., Deblois, T., Ikuta, L., Ginzburg, K., Fleisher, B., \& Koopman, C. (2006). Acute stress disorder among parents of infants in the neonatal intensive care nursery.

Psychosomatics, 47, 206-212.

Stern, M., \& Karraker, K. H., (1990). The prematurity stereotype: Empirical evidence and implications for practice. Infant Mental Health Journal, 11, 3-11.

Stern, M., Karraker, K., McIntosh, B., Moritzen, S., \& Olexa, M. (2006). Prematurity stereotyping and mothers' interactions with their premature and full-term infants during the first year. Journal of Pediatric Psychology, 10, 1-11.

van Beek, Y., Genta, M., Costabile, A., \& Sansavini, A. (2006). Maternal expectations about infant development of pre-term and full-term infants: A cross-national comparison. Infant and Child Development, 15, 41-58.

Verma, R. P., Sridhar, S., \& Spitzer, A. R. (2003). Continuing care of NICU graduates. Clinical Pediatrics, 42, 299-315.

Warren, S. L., Howe, G., Simmens, S. J., \& Dahl, R. E. (2006). Maternal depressive symptoms and child sleep: Models of mutual influence over time. Development and Psychopathology, 18, 1-16. 
Weissbluth, M. (1995). Naps in children: 6 months-7 years. Sleep, 18, 82-87.

Whitney, M. P., \& Thoman, E. B. (1994). Sleep in premature and full-term infants from 24-hour home recordings. Infant Behavior and Development, 17, 223-234.

Wolke, D., Meyer, R., Ohrt, B., Riegel, K. (1995). The incidence of sleeping problems in preterm and full-term infants discharged from neonatal special care units: An epidemiological longitudinal study. Journal of Child Psychology and Psychiatry, 80, 664-671. 
Table 1.

Premature Birth Statistics

\begin{tabular}{ll}
\hline Gestational Age (in weeks) & Percent of All Births \\
\hline Full-term (40+) & 35.15 \\
Full-term (37-39) & 52.36 \\
Premature (34-36) & 8.90 \\
Premature (32-33) & 1.59 \\
Premature (28-31) & 1.25 \\
Premature (<28) & 0.75
\end{tabular}

Note. Data from the National Vital Statistics Report (vol. 55, no. 1), published September 29, 2006, by the Center for Disease Control. 
Table 2 .

Demographic characteristics of late-preterm and full-term infant mothers

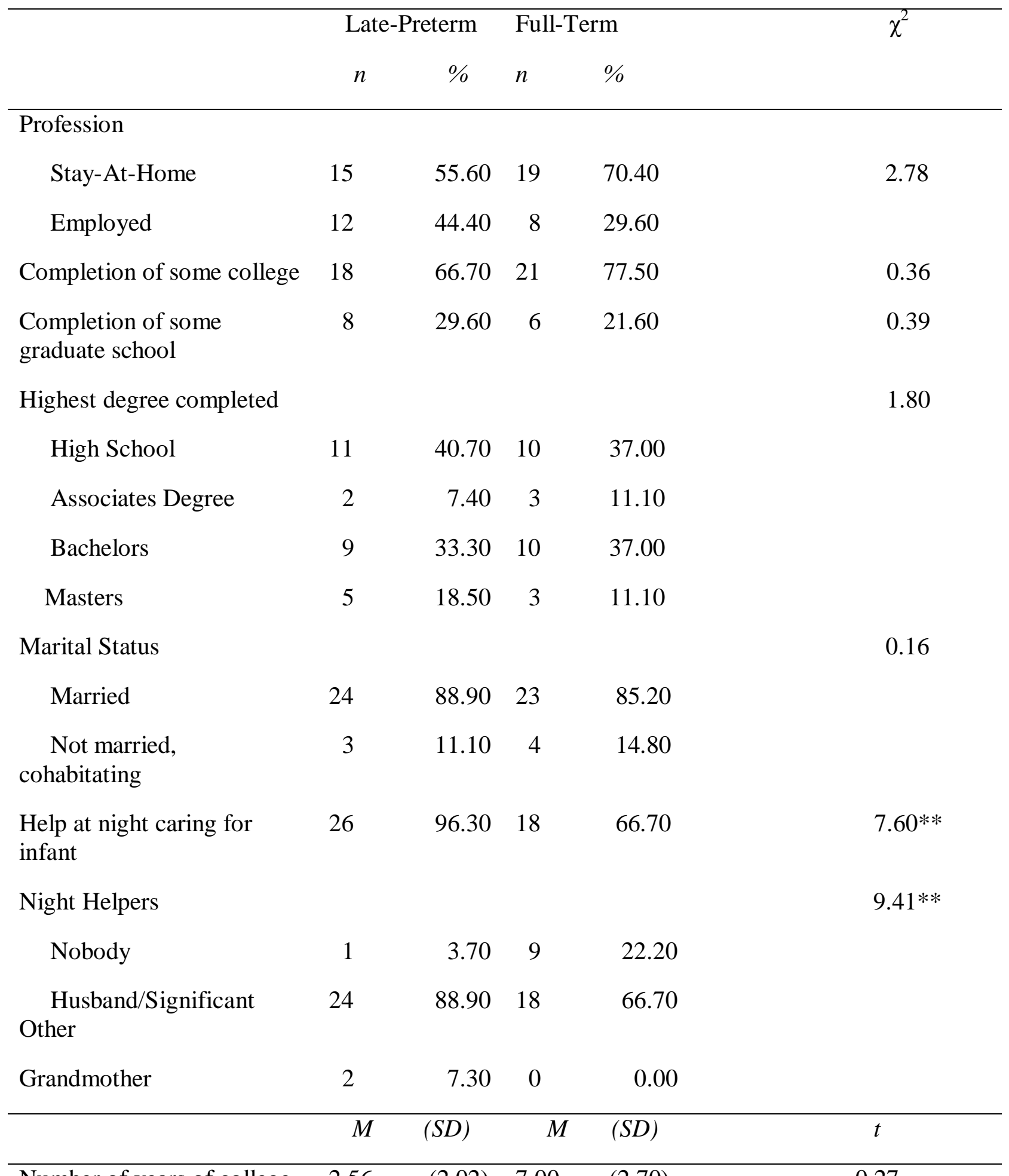

$\begin{array}{lllll}\text { Number of years of college } & 2.56 & (2.02) & 7.00 & (2.70)\end{array}$




$\begin{array}{llllll}\text { Years married } & 6.63 & (4.68) & 6.64 & (5.45) & 0.47 \\ \text { Prior pregnancies } & 2.00 & (0.92) & 2.04 & (2.72) & 1.92 \\ \text { Live births } & 1.44 & (0.51) & 1.93 & (1.54) & 1.53 \\ \text { Children living in the home } & 1.19 & (0.83) & 1.48 & (0.94) & 0.31 \\ \begin{array}{l}\text { Age of children living in the } \\ \text { home }\end{array} & 2.00 & (2.72) & 1.70 & (2.54) & 0.41 \\ \text { Help nights per week } & 3.27 & (2.66) & 3.12 & (1.76) & 0.20\end{array}$
$* \mathrm{p}<.05 . * * \mathrm{p}<.01 . * * * \mathrm{p}<.001$. 
Table 3.

Medical and anthropomorphic measures for late-preterm and full-term infants and mothers

\begin{tabular}{|c|c|c|c|c|c|}
\hline & \multicolumn{2}{|c|}{ Late-Preterm } & \multicolumn{2}{|c|}{ Full-Term } & \multirow[t]{2}{*}{$\chi^{2}$} \\
\hline & $n$ & $\%$ & $n$ & $\%$ & \\
\hline $\begin{array}{l}\text { Problems during } \\
\text { pregnancy }\end{array}$ & & & & & $21.80 * *$ \\
\hline Preeclampsia & 7 & 25.90 & 0 & 0.00 & \\
\hline Gestational & 8 & 29.60 & 4 & 15.00 & \\
\hline \multicolumn{6}{|l|}{ diabetes } \\
\hline Placental & 4 & 14.80 & 3 & 11.00 & \\
\hline \multicolumn{6}{|l|}{ abruption } \\
\hline Premature labor & 1 & 3.70 & 0 & 0.00 & \\
\hline None & 7 & 25.90 & 20 & 74.00 & \\
\hline $\begin{array}{l}\text { Problems during } \\
\text { labor }\end{array}$ & & & & & 7.00 \\
\hline Increased blood & 1 & 3.70 & 0 & 0.00 & \\
\hline \multicolumn{6}{|l|}{ pressure } \\
\hline None & 26 & 96.30 & 27 & 0.00 & \\
\hline Problems at delivery & & & & & $15.13 * *$ \\
\hline Breech & 5 & 18.50 & 1 & 3.70 & \\
\hline Premature & 8 & 29.60 & 0 & 0.00 & \\
\hline SGA & 6 & 22.20 & 0 & 0.00 & \\
\hline None & 8 & 29.60 & 26 & 97.30 & \\
\hline Type of delivery & & & & & $30.68 * *$ \\
\hline Vaginal & 1 & 3.96 & 21 & 77.80 & \\
\hline Cesarean & 26 & 96.04 & 6 & 22.20 & \\
\hline $\begin{array}{l}\text { Major medical } \\
\text { illnesses (yes/no) }\end{array}$ & & & & & 4.40 \\
\hline
\end{tabular}




\begin{tabular}{|c|c|c|c|c|c|}
\hline Gastrointestinal & 1 & 3.70 & 0 & 0.00 & \\
\hline Heart & 1 & 3.70 & 0 & 0.00 & \\
\hline Kidney & 1 & 3.70 & 0 & 0.00 & \\
\hline $\begin{array}{l}\text { Bronchopulmonary } \\
\text { dysplasia }\end{array}$ & 2 & 7.40 & 0 & 0.00 & \\
\hline Pneumonia & 1 & 3.70 & 0 & 0.00 & \\
\hline $\begin{array}{l}\text { Respiratory } \\
\text { syncytial virus }\end{array}$ & 4 & 14.80 & 0 & 0.00 & \\
\hline None & 17 & 63.00 & 27 & 100.00 & \\
\hline $\begin{array}{l}\text { Hospitalized after } \\
\text { release }\end{array}$ & 0 & 0.00 & 0 & 0.00 & \\
\hline Recent colds & & & & & 2.20 \\
\hline Currently & 2 & 7.40 & 2 & 7.40 & \\
\hline Recently & 3 & 11.00 & 6 & 22.00 & \\
\hline None & 22 & 81.00 & 19 & 77.00 & \\
\hline Doctor's visits & & & & & 4.00 \\
\hline Recent & 6 & 21.90 & 6 & 22.00 & \\
\hline None & 21 & 78.10 & 21 & 78.10 & \\
\hline $\begin{array}{l}\text { Completed well baby } \\
\text { visits }\end{array}$ & & & & & 3.10 \\
\hline $\begin{array}{l}2 \& 4 \text { months } \\
\text { only }\end{array}$ & 3 & 11.10 & 7 & 26.00 & \\
\hline $2,4, \& 6$ months & 24 & 88.90 & 20 & 74.00 & \\
\hline $\begin{array}{l}\text { Diagnosed with } \\
\text { reflux }\end{array}$ & 18 & 66.70 & 8 & 30.00 & $7.41 * * *$ \\
\hline $\begin{array}{l}\text { Reflux tx. With } \\
\text { drugs }\end{array}$ & 14 & 51.90 & 6 & 21.90 & $9.01 * *$ \\
\hline $\begin{array}{l}\text { Reflux tx. With } \\
\text { thickening }\end{array}$ & 17 & 63.00 & 3 & 11.00 & $15.90^{* *}$ \\
\hline
\end{tabular}


Type of thickening

\begin{tabular}{|c|c|c|c|c|c|}
\hline Rice & 16 & 59.30 & 3 & 11.00 & \\
\hline Oatmeal & 2 & 7.40 & 0 & 0.00 & \\
\hline None & 9 & 33.30 & 0 & 0.00 & \\
\hline \multirow{2}{*}{$\begin{array}{l}\text { Reflux tx. With } \\
\text { wedge }\end{array}$} & 4 & 14.40 & 1 & 4.10 & \\
\hline & $\mathrm{M}$ & (SD) & $\mathrm{M}$ & (SD) & $\mathrm{T}$ \\
\hline Length of labor & 11.40 & $(16.80)$ & 8.90 & $(10.10)$ & 0.65 \\
\hline $\begin{array}{l}\text { Days infant in } \\
\text { hospital }\end{array}$ & 16.85 & (13.38) & 2.51 & $(0.51)$ & $5.64 * *$ \\
\hline $\begin{array}{l}\text { Age of reflux } \\
\text { diagnosis (weeks) }\end{array}$ & 3.42 & $(3.30)$ & 5.52 & $(2.70)$ & $2.33 * *$ \\
\hline $\begin{array}{l}\text { Amount of } \\
\text { thickening (tsp.) }\end{array}$ & 1.00 & $(0.90)$ & 1.00 & $(0.30)$ & 1.21 \\
\hline
\end{tabular}

$* \mathrm{p}<.05 . * * \mathrm{p}<.01 . * * * \mathrm{p}<.001$. 
Table 4.

Demographic information for late-preterm and full-term infants

\begin{tabular}{|c|c|c|c|c|c|}
\hline & \multicolumn{2}{|c|}{ Late-preterm } & \multicolumn{2}{|c|}{ Full-term } & \multirow[t]{2}{*}{$\chi^{2}$} \\
\hline & $n$ & $\%$ & $n$ & $\%$ & \\
\hline Child's Ethnicity & & & & & 3.01 \\
\hline Caucasian & 24 & $89.10 \%$ & 25 & $91.00 \%$ & \\
\hline Multi-ethnic & 3 & $11.00 \%$ & 2 & $2.00 \%$ & \\
\hline Usual sleeping position & & & & & 0.49 \\
\hline Back & 10 & $37.10 \%$ & 11 & $41.00 \%$ & \\
\hline Tummy & 11 & $41.10 \%$ & 12 & $44.00 \%$ & \\
\hline Side & 6 & $22.00 \%$ & 4 & $15.00 \%$ & \\
\hline Current Feeding Method & & & & & 2.02 \\
\hline Breast and solids & 5 & $18.90 \%$ & 7 & $26.00 \%$ & \\
\hline Bottle and solids & 16 & $59.10 \%$ & 12 & $44.00 \%$ & \\
\hline \multirow[t]{2}{*}{ Breast, bottle, and solids } & 6 & $22.00 \%$ & 8 & $30.00 \%$ & \\
\hline & $M$ & $(S D)$ & $M$ & $(S D)$ & $t$ \\
\hline Gestational age & 34.13 & $(1.71)$ & 39.31 & $(0.68)$ & $14.13 * *$ \\
\hline Corrected age at testing & 6.35 & $(0.56)$ & 6.53 & $(0.75)$ & 0.41 \\
\hline Age of solid foods (months) & 5.11 & $(1.12)$ & 5.04 & $(1.62)$ & 1.23 \\
\hline Feedings per day & 6.32 & $(1.43)$ & 6.62 & $(1.34)$ & 1.00 \\
\hline Current weight (kg) & 6.26 & $5 \quad(1.40)$ & 8.70 & $(1.40)$ & 1.13 \\
\hline Current length (in) & 24.43 & $3 \quad(2.51)$ & 24.43 & $(2.51)$ & 1.34 \\
\hline Current head circumference & 16.74 & $(1.34)$ & 15.92 & $(1.62)$ & $1.88 * *$ \\
\hline
\end{tabular}

$* \mathrm{p}<.05 . * * \mathrm{p}<.01 . * * * \mathrm{p}<.001$. 
Table 5.

Maternal depression history

\begin{tabular}{|c|c|c|c|c|c|c|}
\hline \multirow[t]{2}{*}{ Late-Preterm } & \multicolumn{2}{|c|}{ Prior to Pregnancy } & \multicolumn{2}{|c|}{ During Pregnancy } & \multicolumn{2}{|c|}{ After Pregnancy $\chi^{2}$} \\
\hline & $n$ & $\%$ & $n$ & $\%$ & $n$ & $\%$ \\
\hline $\begin{array}{l}\text { Diagnosed by a } \\
\text { professional }\end{array}$ & 15 & 55.60 & 2 & 7.40 & 10 & $2.70 * *$ \\
\hline \multicolumn{7}{|l|}{ Treatment } \\
\hline Prescription drugs & 14 & 51.90 & 2 & 7.40 & 3.0 & 11.10 \\
\hline Over-the-counter & 0 & 0.00 & 0 & 0.00 & 0 & 0.00 \\
\hline Counseling & 0 & 0.00 & 0 & 0.00 & 0 & 0.00 \\
\hline Other & 0 & 0.00 & 0 & 0.00 & 0 & 0.00 \\
\hline Full-Term & $n$ & $\%$ & $n$ & $\%$ & $n$ & $\%$ \\
\hline $\begin{array}{l}\text { Diagnosed by a } \\
\text { professional }\end{array}$ & 9 & 33.30 & 5 & 18.50 & 5 & 18.90 \\
\hline \multicolumn{7}{|l|}{ Treatment } \\
\hline Prescription drugs & 9 & 33.30 & 2 & 7.40 & 5 & 18.90 \\
\hline Over-the-counter & 2 & 7.40 & 2 & 7.40 & 2 & 7.40 \\
\hline Counseling & 3 & 11.10 & 3 & 11.10 & 3 & 11.10 \\
\hline Other & 2 & 7.40 & 2 & 7.40 & 2 & 7.40 \\
\hline
\end{tabular}

$* \mathrm{p}<.05 . * * \mathrm{p}<.01 . * * * \mathrm{p}<.001$. 
Table 6.

Global maternal scores (average item ratings) for the Brief Symptom Inventory subscales

\begin{tabular}{llll}
\hline & Late-Preterm & Full-term & $T$ \\
\hline Depression & $M(S D)$ & $M(S D)$ & \\
Anxiety & $0.15(0.18)$ & $0.41(0.53)$ & $0.38^{*}$ \\
Hostility & $0.27(0.22)$ & $0.35(0.24)$ & 0.65 \\
Phobic anxiety & $0.30(0.13)$ & $0.25(0.14)$ & 1.64 \\
Psychoticism & $0.13(0.10)$ & $0.30(0.55)$ & 1.86 \\
Global Severity Index & $0.05(0.12)$ & $0.21(0.33)$ & $2.90 * *$ \\
& $0.03(0.01)$ & $0.01(0.01)$ & \\
\hline
\end{tabular}

$* \mathrm{p}<.05 . * * \mathrm{p}<.01 . * * * \mathrm{p}<.001$ 
Table 7 .

Late-preterm and full-term infant sleep indices summary scores (average per 24-hour period)

\begin{tabular}{lccc}
\hline & Late- preterm & Full-term & $F$ \\
& $M(S D)$ & $M(S D)$ & \\
\hline Frequency of night waking & $1.00(0.73)$ & $1.41(1.14)$ & 2.67 \\
$\begin{array}{l}\text { Total time awake at night } \\
\text { (minutes) }\end{array}$ & $10.07(8.98)$ & $9.49(8.81)$ & 2.67 \\
Total night sleep (hours) & $10.32(0.94)$ & $10.49(0.98)$ & 2.67 \\
Frequency of naps & $1.76(0.53)$ & $1.72(0.64)$ & 2.67 \\
Nap length (hours) & $1.00(0.35)$ & $1.59(3.31)$ & 2.67 \\
Total day sleep (hours) & $2.27(1.24)$ & $1.70(0.76)$ & $4.43^{*}$ \\
Total night and day sleep (hrs) & $12.59(1.32)$ & $12.19(1.23)$ & 2.67 \\
\hline
\end{tabular}

$* \mathrm{p}<.05 . * * \mathrm{p}<.01 . * * * \mathrm{p}<.001$ 
Table 8 .

Descriptive information on Bayley expectations

\begin{tabular}{lccccc}
\hline & Late-preterm & & Full-term & \\
& $M$ & $S D$ & $M$ & $S D$ & $F$ \\
\hline $\begin{array}{l}\text { Correctly } \\
\text { expected passes }\end{array}$ & 0.66 & 0.10 & 0.63 & 0.09 \\
$\begin{array}{l}\text { Correctly } \\
\text { expected failures }\end{array}$ & 0.25 & 0.03 & 0.23 & 0.04 & \\
$\begin{array}{l}\text { Overestimations } \\
\text { Underestimations }\end{array}$ & 0.24 & 0.09 & 0.25 & 0.06 & \\
Error type & 0.28 & 0.06 & 0.25 & 0.07 & 0.95 \\
\hline
\end{tabular}


Table 9.

Total scores for the Maternal Cognitions about Infant Sleep Questionnaire, the Vulnerable Child Scale, and the Stern-Karraker Infant Rating Scale

\begin{tabular}{|c|c|c|c|c|c|}
\hline \multirow[b]{3}{*}{ MCISQ Setting Limits } & \multicolumn{2}{|c|}{ Late-Preterm } & \multicolumn{2}{|c|}{ Full-Term } & \multirow[t]{2}{*}{$F$} \\
\hline & $M$ & & $M$ & $(S D)$ & \\
\hline & 2.11 & $(1.00)$ & 2.63 & $(1.05)$ & 2.67 \\
\hline MCISQ Anger & 1.01 & $(0.55)$ & 1.00 & $(0.75)$ & 2.03 \\
\hline MCISQ Doubt & 1.96 & $(0.75)$ & 2.63 & $(1.05)$ & $4.64 *$ \\
\hline MCISQ Feeding & 0.63 & $(0.65)$ & 1.27 & $(1.12)$ & $7.31 *$ \\
\hline MCISQ Safety & 1.63 & $(1.43)$ & 1.31 & $(0.45)$ & 0.93 \\
\hline MCISQ Total & 22.70 & $(8.92)$ & 31.51 & $(13.05)$ & $2.62 * *$ \\
\hline VCS Total Score & 28.03 & $(6.05)$ & 31.43 & $(9.81)$ & 0.72 \\
\hline $\begin{array}{l}\text { Stereotyping Score } \\
\text { (full-term) }\end{array}$ & 4.81 & $(0.95)$ & 5.13 & $(0.54)$ & $4.31 *$ \\
\hline $\begin{array}{l}\text { Stereotyping Score } \\
\text { (premature) }\end{array}$ & 4.95 & $(0.55)$ & 5.03 & $(0.45)$ & 0.54 \\
\hline
\end{tabular}

$* \mathrm{p}<.05 . * * \mathrm{p}<.01 . * * * \mathrm{p}<.001$. 
Late-Preterm and Full-term Infant Sleep 78

Appendix A 

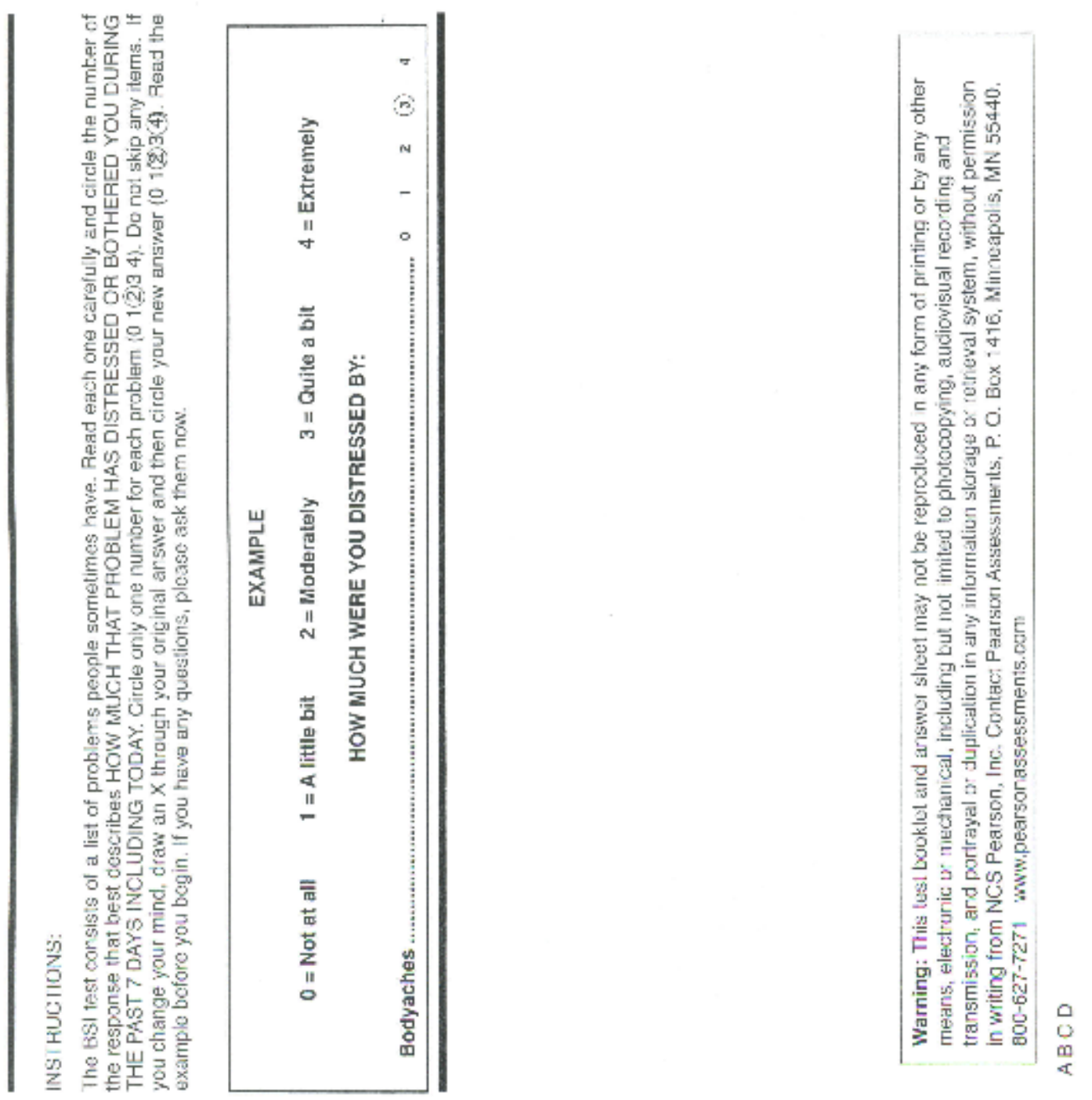


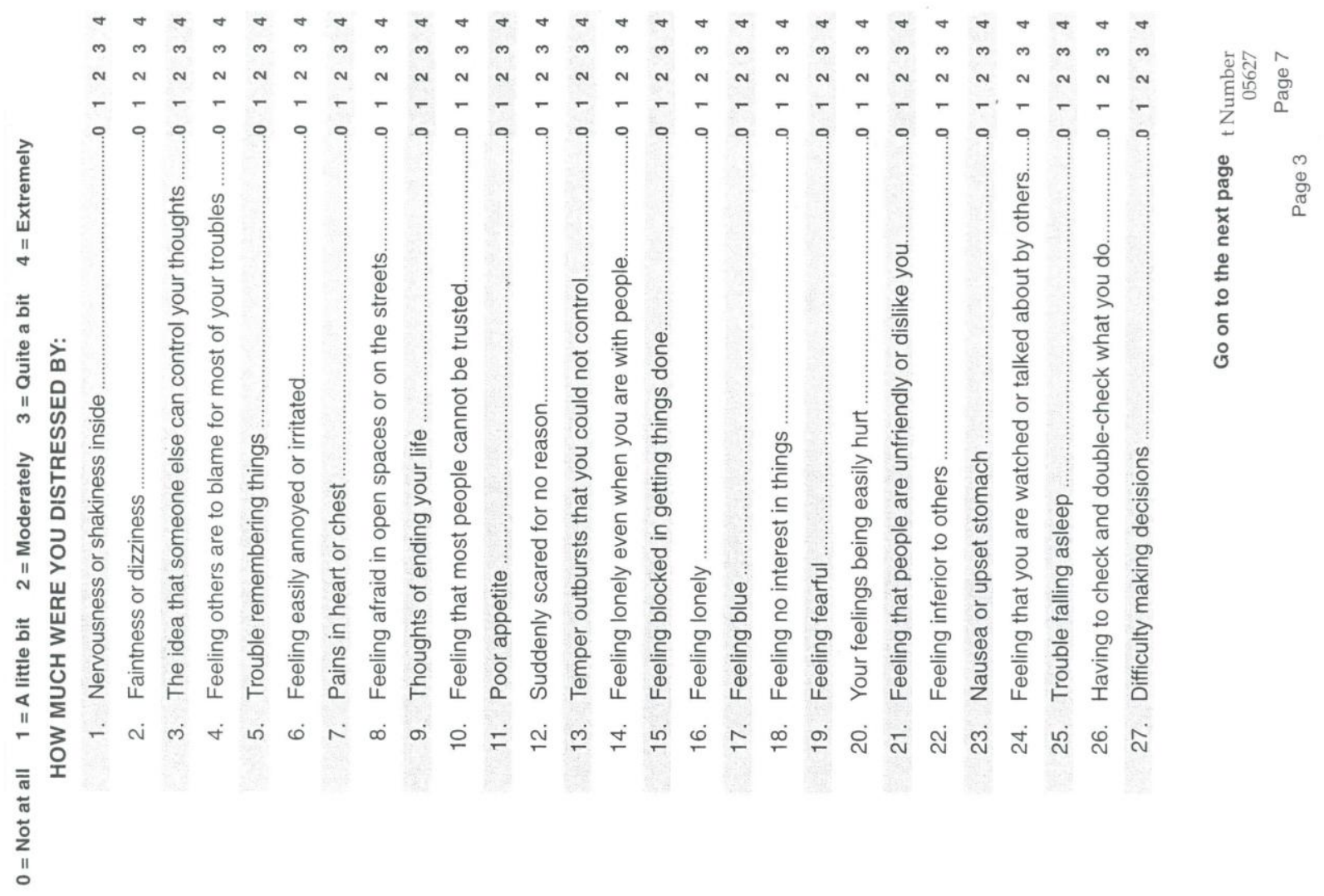



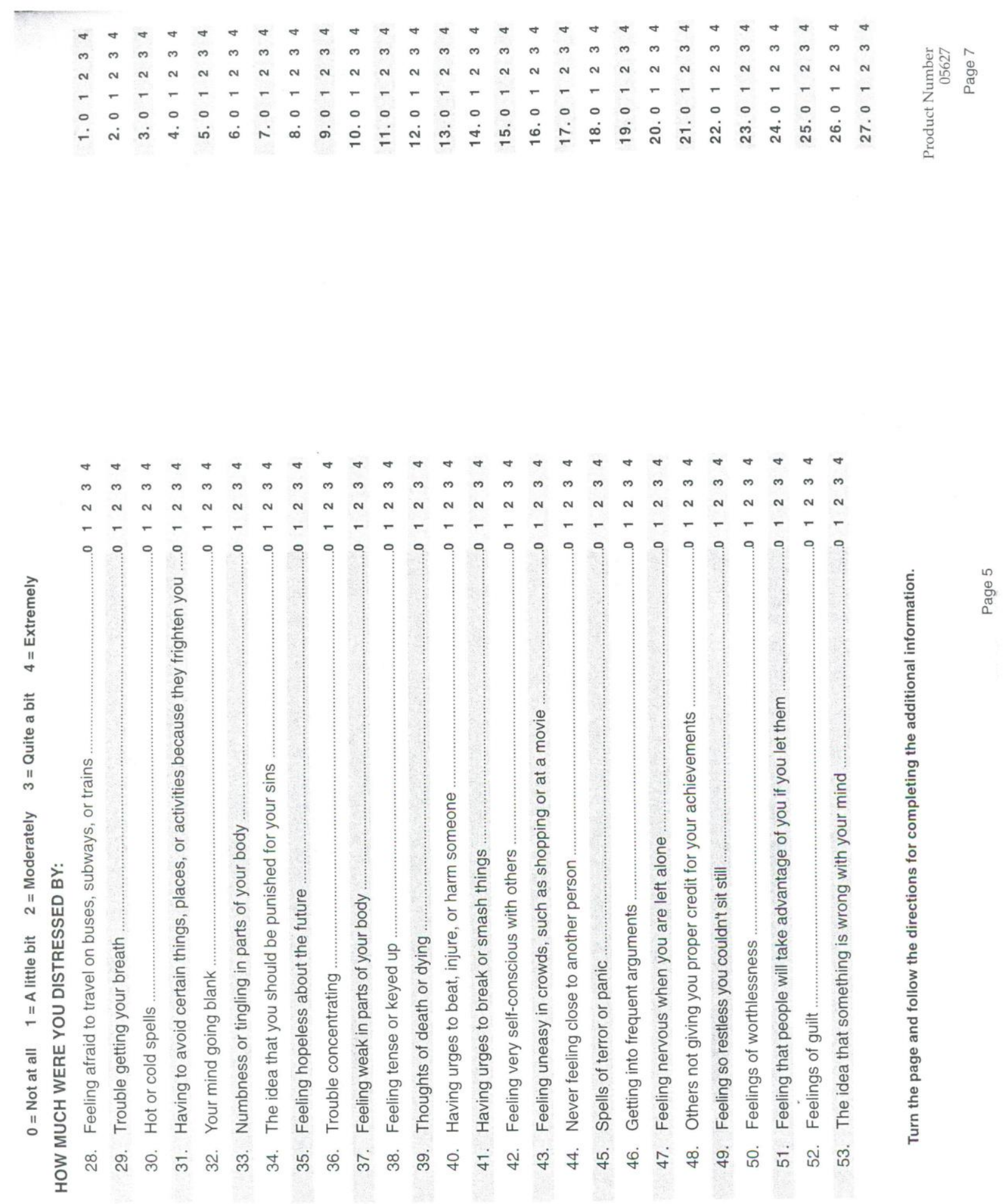
Late-Preterm and Full-term Infant Sleep 82

Appendix B 


\section{Infant and Mother Activity Charts}

The Infant and Mother Activity Charts are designed to give information about how mothers and infants spend their time. Please complete these charts for the weekend before your appointment. Each of the attached charts can be used for one day. The charts are marked off in 15-minute intervals. To use the charts, simply draw a line through the intervals during which you or your infant engage in any of the behaviors listed below. Start completing the charts at 4 p.m. on the Friday preceding your appointment.

On the chart, B stands for baby, and M stands for mother. The behaviors we would like you to record are the following:

Baby sleep

Baby fuss/cry (more than one minute of a 15-minute interval)

Baby eat

Mother sleep (leave an interval blank if you were awake for any part of the interval)

Mother feed baby

Below is a sample chart completed for the time from 8:00 a.m. to 4:00p.m.

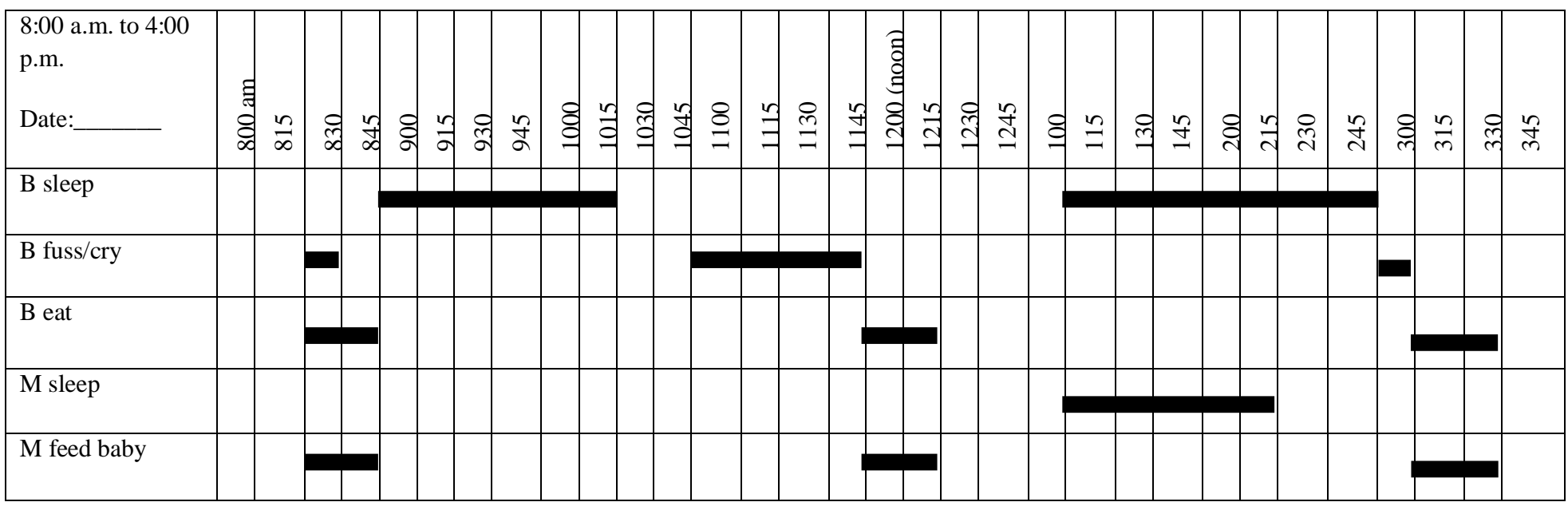




\begin{tabular}{|c|c|c|c|c|c|c|c|c|c|c|c|c|c|c|c|c|c|c|c|c|c|c|c|c|c|c|c|c|c|c|c|}
\hline $\begin{array}{l}4: 00 \text { p.m. to } \\
\text { midnight (Friday) } \\
\text { Date: }\end{array}$ & हี & $\frac{n}{\gamma}$ & ฮิ & 8 & $\frac{n}{n}$ & & $\frac{n}{n}$ & g & $\Rightarrow$ & శ్రి & चे & \& & & $\stackrel{\circ}{\circ}$ & ป & 영 & a & & $\stackrel{n}{+}$ & & $\frac{n}{a}$ & & $\frac{n}{a}$ & & 㝵 & లి & ? & 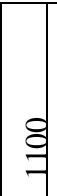 & $\stackrel{n}{\Xi}$ & & $\stackrel{\text { In }}{=}$ \\
\hline B sleep & & & & & & & & & & & & & & & & & & & & & & & & & & & & & & & \\
\hline B fuss/cry & & & & & & & & & & & & & & & & & & & & & & & & & & & & & & & \\
\hline B eat & & & & & & & & & & & & & & & & & & & & & & & & & & & & & & & \\
\hline M sleep & & & & & & & & & & & & & & & & & & & & & & & & & & & & & & & \\
\hline M feed baby & & & & & & & & & & & & & & & & & & & & & & & & & & & & & & & \\
\hline
\end{tabular}

\begin{tabular}{|c|c|c|c|c|c|c|c|c|c|c|c|c|c|c|c|c|c|c|c|c|c|c|c|c|c|c|c|c|c|c|c|c|}
\hline $\begin{array}{l}\text { Midnight to 8:00 } \\
\text { a.m. (Saturday) } \\
\text { Date: }\end{array}$ & 气ే & & 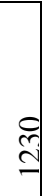 & I & g & $\stackrel{n}{=}$ & & $\stackrel{n}{ \pm}$ & 원 & $\frac{4}{7}$ & సે & ป & ষ্ల & & ల్ల & ने & 의 & 告 & $\stackrel{\vartheta}{7}$ & $\stackrel{n}{g}$ & & $\frac{n}{n}$ & & in & 웡 $\frac{n}{6}$ & $\frac{1}{6}$ ) & fa & & $\frac{9}{7}$ & & & $\stackrel{\text { I }}{i}$ \\
\hline B sleep & & & & & & & & & & & & & & & & & & & & & & & & & & & & & & & & \\
\hline B fuss/cry & & & & & & & & & & & & & & & & & & & & & & & & & & & & & & & & \\
\hline$B$ eat & & & & & & & & & & & & & & & & & & & & & & & & & & & & & & & & \\
\hline M sleep & & & & & & & & & & & & & & & & & & & & & & & & & & & & & & & & \\
\hline M feed baby & & & & & & & & & & & & & & & & & & & & & & & & & & & & & & & & \\
\hline
\end{tabular}




\begin{tabular}{|c|c|c|c|c|c|c|c|c|c|c|c|c|c|c|c|c|c|c|c|c|c|c|c|c|c|c|c|c|c|c|}
\hline $\begin{array}{l}\text { 4:00 p.m. to } \\
\text { midnight } \\
\text { (Saturday) } \\
\text { Date: }\end{array}$ & है & & $\stackrel{q}{q}$ & & $=\frac{n}{n}$ & 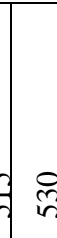 & if & & $\frac{7}{3}$ & व્ఠి & 겅 & 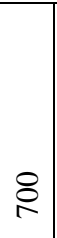 & & i & I & 영 & s. & ભ & 赵 & & $\frac{n}{a}$ & & そ) & 웅 음 & a. & 帒 & g & $\stackrel{n}{\Xi}$ & $\stackrel{0}{=}$ & $\stackrel{n}{=}$ \\
\hline B sleep & & & & & & & & & & & & & & & & & & & & & & & & & & & & & & \\
\hline B fuss/cry & & & & & & & & & & & & & & & & & & & & & & & & & & & & & & \\
\hline B eat & & & & & & & & & & & & & & & & & & & & & & & & & & & & & & \\
\hline M sleep & & & & & & & & & & & & & & & & & & & & & & & & & & & & & & \\
\hline $\begin{array}{l}\text { Midnight to 8:00 } \\
\text { M feed baby } \\
\text { a.m. (Sunday) }\end{array}$ & & & & & & & & & & & & & & & & & & & & & & & & & & & & & & \\
\hline Date: & $\stackrel{0}{ป}$ & $\frac{n}{1}$ & ฮิ & f & 年 & $\theta 9$ & $\stackrel{\text { If }}{ \pm}$ & 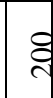 & 7 & స్తి & 年 & ষ্ল & & ల్ల & If & 워 & 斗 & & $\stackrel{f}{f}$ & : & $\frac{n}{n}$ & ज्ञ & in & 웅 $\frac{10}{0}$ & $\frac{1}{0} \frac{0}{0}$ & if & ₹ & $\frac{n}{2}$ & $\stackrel{2}{7}$ & $\stackrel{n}{q}$ \\
\hline B sleep & & & & & & & & & & & & & & & & & & & & & & & & & & & & & & \\
\hline B fuss/cry & & & & & & & & & & & & & & & & & & & & & & & & & & & & & & \\
\hline B eat & & & & & & & & & & & & & & & & & & & & & & & & & & & & & & \\
\hline M sleep & & & & & & & & & & & & & & & & & & & & & & & & & & & & & & \\
\hline M feed baby & & & & & & & & & & & & & & & & & & & & & & & & & & & & & & \\
\hline
\end{tabular}

\begin{tabular}{|c|c|c|c|c|c|c|c|c|c|c|c|c|c|c|c|c|c|c|c|c|c|c|c|c|c|c|c|c|c|c|c|c|}
\hline $\begin{array}{l}\text { 8:00 a.m. to 4:00 } \\
\text { p.m. (Sunday) } \\
\text { Date: }\end{array}$ & हี & $\frac{n}{\infty}$ & $\stackrel{\sim}{\propto}$ & जf & 을 & $\frac{n}{8}$ & & $\frac{a}{2}$ & : & 皕 & ฮิ & & $\underset{\Xi}{\stackrel{8}{\prime}}$ & & 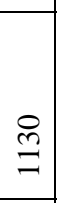 & $\exists$ & 司 & 고 & & $\stackrel{\text { I }}{\beth}$ & & $\cong$ & ले & $\stackrel{?}{ \pm}$ & 워 & & $\stackrel{\sim}{\approx}$ & $\stackrel{\text { I }}{d}$ & & $\frac{n}{m}$ & & 年 \\
\hline B sleep & & & & & & & & & & & & & & & & & & & & & & & & & . & & & & & & & \\
\hline B fuss/cry & & & & & & & & & & & & & & & & & & & & & & & & & & & & & & & & \\
\hline B eat & & & & & & & & & & & & & & & & & & & & & & & & & & & & & & & & \\
\hline M sleep & & & & & & & & & & & & & & & & & & & & & & & & & & & & & & & & \\
\hline M feed baby & & & & & & & & & & & & & & & & & & & & & & & & & & & & & & & & \\
\hline
\end{tabular}




\begin{tabular}{|c|c|c|c|c|c|c|c|c|c|c|c|c|c|c|c|c|c|c|c|c|c|c|c|c|c|c|c|c|c|c|c|}
\hline $\begin{array}{l}\text { 4:00 p.m. to } \\
\text { midnight } \\
\text { (Sunday) } \\
\text { Date: }\end{array}$ & 章 & & ริ & fo & $\frac{n}{n}$ & & in & & 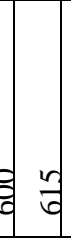 & 月 & 岛 & 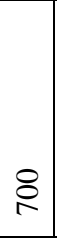 & & $\stackrel{2}{\sim}$ & ป & 青 & क्ने & लू & in & & $\frac{n}{\sigma}$ & वे & 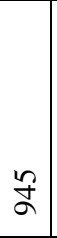 & 읭 & $\frac{1}{0}$ & I & & 寻告 & & & $\stackrel{?}{=}$ \\
\hline B sleep & & & & & & & & & & & & & & & & & & & & & & & & & & & & & & & \\
\hline B fuss/cry & & & & & & & & & & & & & & & & & & & & & & & & & & & & & & & \\
\hline B eat & & & & & & & & & & & & & & & & & & & & & & & & & & & & & & & \\
\hline M sleep & & & & & & & & & & & & & & & & & & & & & & & & & & & & & & & \\
\hline $\begin{array}{l}\text { M feed baby } \\
\text { a.m. (Monday) }\end{array}$ & & & & & & & & & & & & & & & & & & & & & & & & & & & & & & & \\
\hline Date: & $\stackrel{0}{0}$ & $\stackrel{n}{\simeq}$ & 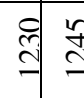 & f & 年 & 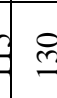 & 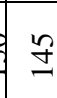 & & $\frac{4}{7}$ & ते & ป & ষ্ল & & ల్ల & mे & 워 & & & $\stackrel{f}{q}$ & : & $\frac{n}{n}$ & भी & $\stackrel{n}{n}$ & 웡 $\frac{n}{6}$ & $\frac{1}{0}$. & ? & & $\frac{9}{7}$ & $\Leftrightarrow$ & ले & $\stackrel{n}{i}$ \\
\hline B sleep & & & & & & & & & & & & & & & & & & & & & & & & & & & & & & & \\
\hline B fuss/cry & & & & & & & & & & & & & & & & & & & & & & & & & & & & & & & \\
\hline B eat & & & & & & & & & & & & & & & & & & & & & & & & & & & & & & & \\
\hline M sleep & & & & & & & & & & & & & & & & & & & & & & & & & & & & & & & \\
\hline M feed baby & & & & & & & & & & & & & & & & & & & & & & & & & & & & & & & \\
\hline
\end{tabular}

Did you cosleep with your infant? Yes or no.

How many times at night did you check on your infant without him/her crying? 
Late-Preterm and Full-term Infant Sleep 87

Appendix C 


\section{Maternal Cognitions about Infant Sleep Questionnaire}

Here are a series of statements about thoughts and feelings mothers may have when faced with a child that won't sleep. After reading each statement indicate the statement that most closely represents how you yourself would feel with your infant. Don't take too long thinking about your answer and don't hesitate to use the extreme responses if appropriate.

\begin{tabular}{|c|c|c|c|c|c|}
\hline 0 & 1 & 2 & 3 & 4 & 5 \\
\hline Strongly & $\begin{array}{c}\text { Moderately } \\
\text { Disagree }\end{array}$ & $\begin{array}{c}\text { Mildly } \\
\text { Disagree }\end{array}$ & Mildly Agree & $\begin{array}{c}\text { Moderately } \\
\text { Agree }\end{array}$ & $\begin{array}{c}\text { Strongly } \\
\text { Agree }\end{array}$ \\
\hline
\end{tabular}

$1 \ldots$ When my child cries at night, I think something awful might have happened to him/her.

2 ___ When my child wakes at night, I think I might not have fed him/her enough during the day.

3 ___ My child might die unexpectedly in his/her sleep.

$4 \ldots$ My child will feel abandoned if I don't respond immediately to his/her cries at night.

5 __ My child might go hungry if I don't give him/her a feed at night.

$6 \ldots$ It is all right to allow my child to cry at night.

7 W_ When my child cries at night, I think I might lose control and harm him/her.

8 When my child wakes at night, I think I might not have given him/her enough attention during the day.

9 _ I should be getting up during the night to check that my child is still all right.

$10 \ldots$ _ If I try to resist my child's demands at night, then I think I might get very angry.

11 When my child wakes crying, I always know what he/she needs.

12 __ When my child cries at night and needs me, I wish he/she wasn't so demanding.

13 _ If I try to resist my child's demands at night, then he/she will get even more upset.

$14 \ldots$ When my child doesn't sleep at night, I doubt my competence as a parent.

15 _ If I say no to my child's demands at night, then that means I'm a bad mother.

$16 \ldots$ I am able to let my child sleep on his/her own. 
17 W When my child cries at night, I can find myself thinking I wish I had never had a child.

18 _ I should respond straightaway when my child wakes crying at night.

19 _ I am able to resist my child's demands when he/she wakes at night.

20 __ If I give up feeding at night, then he/she will never sleep. 
Late-Preterm and Full-term Infant Sleep 90

Appendix D 


\section{$\underline{\text { Infant Sleep Vignettes Interpretation Scale }}$}

In the following questionnaire, you will find several descriptions of babies at different ages. After each description several statements will appear. Please indicate your degree of agreement with each statement according to the scale below. There is no right or wrong answer. Please answer according to your own beliefs. Thank you for your cooperation!

\begin{tabular}{|l|l|l|l|l|l|}
\hline 1 & 2 & 3 & 4 & 5 & 6 \\
\hline $\begin{array}{l}\text { Strongly } \\
\text { Disagree }\end{array}$ & Disagree & $\begin{array}{l}\text { Somewhat } \\
\text { Disagree }\end{array}$ & $\begin{array}{l}\text { Somewhat } \\
\text { Agree }\end{array}$ & Agree & $\begin{array}{l}\text { Strongly } \\
\text { Agree }\end{array}$ \\
\hline
\end{tabular}

1. Mary is a 6-month-old girl. She is described as an anxious baby during the day. She finds it hard to separate from her parents and cries when her mother leaves the room. She reacts to every change or a new face. Every night she wakes up crying 4-5 times and finds it difficult to fall back asleep.

It is necessary to check on Mary when she wakes up and to calm her down and help her to fall asleep again.

It is Mary's nature to wake up at night and it will be difficult to change this behavior.

One should resist Mary's demands when she wakes up at night. This will help her learn to fall asleep on her own.

2. Susan is an 18-month-old girl. She is described as a restless child. She is very active at her daycare center and finds it hard to fall asleep there. At home, she does not want to sleep and behaves nervously. At night, she has difficulty falling asleep. Susan's older brother resembles her in his restlessness and his sleep problems.

There are children who find it hard to fall asleep and it is difficult to change this tendency.

Susan's demands should be resisted and her parents should avoid going to her during the night, so that she learns to fall asleep on her own.

Susan's parents should stay with her and calm her down until she falls asleep. 
3. Tom is a 9-month-old boy. When he wants something or feels uncomfortable he cries and screams loudly. He usually calms down quickly when he gets what he wanted. During the night, Tom wakes up many times and has difficulties falling asleep.

It is better not to react each time Tom wakes up so that he can learn to calm down and fall asleep.

There are children who habitually wake up at night and it is hard to change this behavior.

One should go to Tom when he wakes up, so that he knows that there is always someone to soothe him.

4. Dan is a 2-year-old boy. He is a curious child who is interested in every object at home. His motor development was fast and he started walking at an early age. Dan finds it difficult to fall asleep at bedtime.

Dan's difficulty in falling asleep is in his nature, which is difficult to influence.

Dan is probably frightened and therefore one should go to him and help him fall asleep.

Dan's parents should resist his demands and avoid going to him at night so that he can learn to fall asleep alone.

5. Sue is a 20-month-old girl and attends a daycare center. Every morning when entering the center, she has difficulty separating from her mother. Her mother calms her down and helps her take part in the activities. At night Sue wakes up 4-5 times, finding it hard to calm down and resume sleep.

It is okay to let Sue cry when she wakes up. She should learn to fall asleep on her own.

Sue's parents should go to her and help her to calm down.

It is Sue's nature to wake up and it is difficult to find a way to help her.

6. Kevin is an 8-month-old boy. He is described as a very active and alert child. He is restless, cries a lot, and his parents have a hard time calming him down. Kevin's father 
reported that he himself was an active and restless child. During the night, Kevin wakes up a number of times and has difficulty falling asleep.

One should allow Kevin to cry at night. This will teach him to fall asleep by himself.

Kevin's parents should react immediately to his crying; otherwise he will feel abandoned.

It is probably Kevin's nature to wake up often at night.

7. Judi is a 21-month-old girl. She is described as a stubborn child in certain situations, but after a talk and explanation, she usually cooperates. Judi finds it hard to fall asleep at night.

Judi's parents should react every time she has difficulty falling asleep, so that she will not feel abandoned.

Judi's difficulty falling asleep is part of her nature, and it is hard to change this problem.

Judi's parents should insist on her falling asleep alone, so that she won't learn to manipulate them.

8. Ron is a 9-month-old boy. He is a cheerful child who smiles a lot. Ron is very attached to his parents. When Ron is restless or cries, he calms down when his parents are near him. At bedtime, it takes him a long time to fall asleep.

Ron's difficulty falling asleep is related to his temperament and therefore it would be hard to change it.

Ron's parents should let him fall asleep on his own, so that he can learn to be independent.

Ron's parents should soothe him and help him to fall asleep.

9. Rachel is a 10-month-old girl. She is described as an alert and nervous child. She is restless in any situation whether she is alone or with her parents. Rachel wakes up a number of times at night, and finds it hard to return to sleep. 
It is Rachel's nature to wake up at night and it is hard to find a way to help her.

Rachel wakes up because she is scared, and her parents should go to her and soothe her.

Rachel's parents should avoid going to her or she will be even more nervous.

10. Jewel is a 6-month-old girl. Her motor development has been fast. A babysitter has been caring for her since she was 3 months old and Jewel likes to go outside with her. Jewel wakes up crying several times at night and it is hard to comfort her.

Jewel's parents should let her fall asleep on her own; otherwise she will be dependent on her parents.

There are children who have a tendency to wake up at night, and who have difficulty falling asleep. It is hard to change this pattern.

Jewel is probably frightened; therefore, someone should go to her when she wakes up and comfort her.

11. Ruth is a 9-month-old girl. When she does not want to stay in her crib, she cries inconsolably. When she wants something, she yells and cries until she gets what she wants. Ruth finds it very difficult to fall asleep at night.

There are children who naturally find it hard to fall asleep, and it is probably difficult to change this.

Ruth is probably scared; therefore, someone should be with her until she falls asleep.

Ruth's parents should resist her demands, and avoid going to her, so that she can learn to fall asleep on her own.

12. James is a 2-year-old boy. He is described as an anxious child who becomes scared easily. He resists separating from his parents or from his caregiver at his daycare center. He finds it very difficult to fall asleep at night.

James' difficulty falling asleep is part of his character and therefore it will be hard to change. 
James is probably frightened; therefore, one should go to him and help him fall asleep.

James should be given the opportunity to fall asleep on his own; otherwise he will become dependent on his parents.

13. John is an 8-month-old boy. He is described as an active and restless child since he was born. His older brothers are both described as very active. When John is put into bed, it takes him a lot of time to fall asleep.

It is better to stay with John and soothe him until he falls asleep.

It is okay to let John fall asleep on his own, even if takes him a lot of time.

John's difficulty falling asleep is related to his temperament; therefore, it would be difficult to change.

14. Steve is a 21-month-old boy. He is described as a very obstinate child. At home, there are many power struggles around eating, playing, and different activities. Steve wakes up several times at night and it is hard to soothe him. On the other hand, Steve sleeps well in his daycare center.

It is important to resist Steve's demands at night, so that he will learn to fall asleep on his own.

One of Steve's basic traits causes him to wake up at night.

Steve's parents should soothe him; otherwise he might feel frightened and lonely. 
Late-Preterm and Full-term Infant Sleep 96

Appendix E 


\section{Vulnerable Child Scale}

Please rate the following statements using the scale below:

\begin{tabular}{|c|c|c|c|}
\hline 1 & 2 & 3 & 4 \\
\hline Definitely & Mostly & Mostly & Definitely \\
False & False & True & True \\
\hline
\end{tabular}

1. __ In general, my child seems to be less healthy than other children of the same age.

2. __ I often think about calling the doctor about my child.

3. __ When there is something going around, my child usually catches it.

4. __ My child seems to have more accidents and injuries than other children.

5. ___ My child usually has a healthy appetite.

6. __ Sometimes I get concerned that my child doesn't look as healthy as he/she should.

7. _ _ My child usually gets stomach pains or other sorts of pains.

8. _ _ I often have to keep my child indoors because of health reasons.

9. _ My child seems to have as much energy as other children of the same age.

10. __ My child gets more colds than other children of the same age.

11. I I get concerned about circles under my child's eyes.

12. _ I often check on my child at night to make sure he/she is okay.

13. I I sometimes worry that my child will die.

14. _ I I feel anxious about leaving my child with a babysitter or at day care.

15. _ I I sometimes am unsure about my ability to care for my child as well as I should.

16. _ I I feel guilty when I have to punish my child. 
Late-Preterm and Full-term Infant Sleep 98

Appendix F 


\section{Bayley Expectations Questionnaire}

We will be administering the items described and illustrated below from the Bayley Scales of Infant and Toddler Development to your infant. We are interested in your expectations concerning your infant's ability to perform these items. For each item, please predict whether or not your infant will be able to do the action described. If you don't understand an item from the description, ask the test administrator for further explanation or a demonstration of the item.

1. Explores rattle, showing interest in detail. The examiner will place the rattle in your infant's hand. Will your infant touch, shake mouth, or engage in other playful activity

with the rattle? YES NO

Will your infant look at or hold the rattle? YES NO

2. Carries bracelet to mouth. The examiner will place the bracelet in your infant's hand.

Will your infant bring the bracelet to his/her mouth? YES NO

3. Inspects own hand.

Will your infant inspect on or both of his/her hands? YES NO

4. Approaches mirror image. The examiner will place a mirror in front of your infant and then watch his/her reaction.

Will your infant reach for the mirror and engage with their reflection? YES

NO

5. Persistent reach, the examiner will place a block on the table in front of your child just out of his/her reach.

Will your infant reach for the object, even if he/she cannot grasp it the first time? YES NO

6. Plays with string. The examiner will dangle a plastic ring (about 4 " in diameter) by an attached string and then place it on the table.

Will your infant play with the string by picking it up, chewing it, or mouthing it?

YES NO 
7. Bangs in play. The examiner will hand your infant a block or spoon.

During the test, will your infant bang the black or spoon on the table? YES NO

8. Calms when spoken to.

During the test, if your infant becomes fussy, will he/she calm when spoken to without having to be touched or held? YES NO

9. Reacts to sounds in the environment.

During the test, will your infant react to (turning head or startling) sounds in the environment? YES NO

10. Responds to a person's voice.

During the test, will your infant respond to a person's voice by turning his/her head, startling, vocalizing, or by changing facial expressions?

YES NO

11. Searches with head turn. The examiners will stand beside your infant and hold a bell near the infant's right ear. The examiner will then ring the bell gently. The examiner will then do the same thing with the left ear.

Will your infant turn his/her head toward the source of the sound at least once?

YES NO

12. Discriminates sounds. The examiner will stand beside the infant and crumple paper behind the infant's left ear. The sound will continue until the infant no longer searches for the sound. Then the examiner will gently shake the rattle, in the same place.

Will your infant respond to the sound of the rattle by startling, turning his/her

head, changing facial expressions, or vocalizing? YES NO

13. Vocalizes mood.

During testing, will your infant produce expressive vocalizations to indicate

pleasure, displeasure, eagerness, or satisfaction? YES NO

14. Social vocalizing or laughing.

During the test, will your infant respond to the examiner by giggling, cooing, or squealing? YES NO

15. Vocalizes two different vowel sounds (ah, uh, oo, eh).

During the test, will your infant make two different vowel sounds?

YES NO

16. Grasps suspended ring. The examiner will dangle a plastic ring (about 4 " in diameter) by an attached string.

Will your infant use at least one hand to grasp the ring for at least two seconds? YES NO 
17. Block Series. The examiner will place a block on the table, directly in front of the infant, and within his/her reach.

Will your infant extend one or both arms forward to reach the block? YES NO

Will your infant extend one or both arms forward and touch the block?

YES NO

Will your infant extend one or both arms forward and pick up the block using one or both hands? YES NO

18. Food Pellet. The examiner will place a cheerio 10 inches from the edge of the table, in front of your infant.

Will your infant rake the pellet toward him/her while attempting to grasp it?

YES NO

19. Motor skills. Which of the following skills will your infant be able to demonstrate?

Hold his/her head erect and steady for at least 15 seconds without support

YES NO

Holds his/her head erect and steady without support while being moved

YES NO

Maintains a raised head at least 45 degrees from the floor when on his/her stomach for at least 2 seconds

YES NO

Keeps head balanced and in the same plane as his/her body when he/she is moved YES NO

Actively turns from both sides to his/her back

YES NO

Elevates his/her head and upper trunk by pushing up on his/her elbows or forearms when on the stomach

YES NO

Sits with support briefly

YES NO

While on the stomach raises head to at least 90 degrees for 5 seconds

YES NO

Sits with light support for at least 30 seconds

YES NO

Turns from his/her back to both the right and left sides

YES NO

Elevates his/her head and upper trunk by supporting weight on both hands YES NO 
Appendix G 


\section{Background Information Form}

Mother's Name

Profession

Age

Have you completed some college?

Yes

No

If yes, how many years?

Have you completed some graduate school? Yes No

If yes, how many years?

Highest Degree Completed

Marital Status (Please circle one):

Married

Divorced

Not Married, Cohabitating

Not Married or Cohabitating

If married, number of years you have been married

Child's Ethnicity (Please Circle One):

Caucasian

Hispanic

African-American

Asian/Pacific Islander

American Indian

Multi-Ethnic

Other

Number of prior pregnancies:

Number of live births:

Number of children living in your home:

Ages:

Do you have any help at night caring for your infant? Yes No 
If yes, how many nights per week do you have help at night caring for your infant?

Who helps you care for your infant at night?

\section{$\underline{\text { History of Depression }}$}

For the table below please indicate any experience of depression (at least two weeks of feeling blue) prior to, during, and since pregnancy. Please also indicate what methods you used to treat your depression, if any.

\begin{tabular}{|c|c|c|c|}
\hline Depression & Prior to Pregnancy & During Pregnancy & Since Pregnancy \\
\hline $\begin{array}{l}\text { Diagnosed by a } \\
\text { professional? }\end{array}$ & Yes $\quad$ No & Yes $\quad$ No & Yes \\
\hline $\begin{array}{l}\text { Treatment: } \\
\text { Prescription } \\
\text { Medications }\end{array}$ & & & \\
\hline $\begin{array}{l}\text { Over-the-Counter } \\
\text { Medications }\end{array}$ & & & \\
\hline Counseling & & & \\
\hline Other & & & \\
\hline
\end{tabular}

Information about your baby

Birth date:

Due date:

Type of delivery: $\quad$ Vaginal

Cesarean

Problems during pregnancy:

Problems during labor:

Length of labor: hours

Problems at delivery: Breech birth 


\section{Premature}

Small for gestational age

Medical problems present at birth

Specify:

How many days was your infant in the hospital following his/her birth? days

Please list any medical problems your baby has had since birth:

Please list any current or recent (in the last four weeks) illnesses your baby has had:

Has your infant been hospitalized after release from the Neonatal Intensive Care Unit (NICU)? If yes, for what reason and for how long?

Usual Infant Sleeping Position(s) Back Tummy Side

$\underline{\text { Recent Colds (in the last four weeks): }}$

When?

Recent doctor's visits (in the last four weeks):

When?

Please circle the Well-Baby Visits that your infant has completed:

2-months 4-months 6-months

\section{Nutritional Status:}

When (in weeks since birth) has your infant been breast-fed?

When (in weeks since birth) has your infant been solely bottle fed?

When (in weeks since birth) has your infant been both breast and bottle fed?

Do you feed your infant solid foods? $\quad$ YES NO

If yes, at what age did you start feeding your infant solid food?

What is your current feeding method? 
Number of feedings per day?

\section{History of Reflux:}

In the table below please indicate if your infant has or has not been diagnosed with reflux. If your infant has been diagnosed please also indicate what methods you used to treat his/her reflux.

\begin{tabular}{|l|l|}
\hline Reflux & Age of Diagnosis \& Treatment (xx to xx weeks) \\
\hline Diagnosed? Yes No $\quad$ Prescription Medications (Please list): & \\
\hline Treatment (Please circle below all that apply): & \\
\hline Thickening of Feeds (How much \& what type): & \\
\hline Sleeping Wedge & \\
\hline
\end{tabular}

Current weight:

Current length:

Current head circumference: 